

\section{/MCP}

Editor-in-Chief

Frederic R. Curtiss, PhD, RPh, CEBS

830.935.4319,fcurtiss@amcp.org

Managing Editor

Diane P. Britton

dbritton@amcp.org

Peer Review Administrator

Jennifer A. Booker, 703.317.0725

jmcpreview@amcp.org

\section{Graphic Designer}

Kathleen Furey/Furey Design

Leslie Goodwin, lgoodwin@amcp.org

\section{Account Manager}

Peter Palmer, 856.795.5777, ext. 13

peter@promedgroup.net

\section{Publisher}

Judith A. Cahill, CEBS

Executive Director

Academy of Managed Care Pharmacy

This supplement to the Journal of Managed Care Pharmacy (ISSN 1083-4087) is a publication of the Academy of Managed Care Pharmacy, 100 North Pitt St., Suite 400, Alexandria, VA 22314; 703.683.8416; 703.683.8417 (fax).

Copyright $(2007$, Academy of Managed Care Pharmacy. All rights reserved. No part of this publication may be reproduced or transmitted in any form or by any means, electronic or mechanical, without written permission from the Academy of Managed Care Pharmacy.

POSTMASTER: Send address changes to JMCP, 100 North Pitt St., Suite 400, Alexandria, VA 22314

\section{Supplement Policy Statement}

Standards for Supplements to the Journal of Managed Care Pharmacy

Supplements to the Journal of Managed Care Pharmacy are intended to support medical education and research in areas of clinical practice, health care quality improvement, or efficient administration and delivery of health benefits. The following standards are applied to all JMCP supplements to ensure quality and assist readers in evaluating potential bias and determining alternate explanations for findings and results.

1. Disclose the principal sources of funding in a manner that permits easy recognition by the reader.

2. Disclose the existence of all potential conflicts of interest among supplement contributors, including financial or personal bias.

3. Describe all drugs by generic name unless the use of the brand name is necessary to reduce the opportunity for confusion among readers

4. Strive to report subjects of current interest to managed care pharmacists and other managed care professionals.

5. Seek and publish content that does not duplicate content in the Journal of Managed Care Pharmacy.

6. Subject all supplements to expert peer review.
FACULTY

Wendy L. St. Peter, PharmD, FASN, FCCP, BCPS, is an associate professor, Department of Pharmaceutical Care and Health Systems, College of Pharmacy at the University of Minnesota, Minneapolis. A nephrology pharmacy practitioner since 1988, she is a board-certified specialist in pharmacotherapy and is a member of many professional organizations, including the National Kidney Foundation (NKF) and the American Society of Nephrology.

St. Peter is also an investigator with the Chronic Disease Research Group and the United States Renal Data System (USRDS). She is involved in analytical research using Medicare and other large patient databases with the USRDS Coordinating Center, Hennepin County Medical Center, Minneapolis. St. Peter served as a technical expert panel member (TEP) for the Center for Medicare \& Medicaid Services' (CMS') End-Stage Renal Disease (ESRD) Outpatient Medications Project and the CMS' TEP for the Chronic Kidney Disease/ESRD Medication Measures Project. She has provided her expertise to the NKF Kidney Medicare Drugs Awareness and Education Initiative to help address the complexity of Medicare Part D

Harold J. Manley, PharmD, FASN, FCCP, BCPS, is director, clinical pharmacy, VillageHealth Disease Management, Glenmont, New York. His academic degrees include a BS in Pharmacy (1993) and a PharmD (1996). He completed an internal medicine/primary care pharmacy residency in 1997 and a 2-year nephrology pharmacy fellowship in 1999. Manley served on the Center for Medicare \& Medicaid Services' ESRD Network 8 Outpatient Medication Project to produce an outpatient medication formulary. He is a board-certified specialist in pharmacotherapy and is a member of many professional organizations, including the American Society of Nephrology, the American College of Clinical Pharmacy, and the National Kidney Foundation. Manley is a fellow of the American Society of Nephrology and American College of Clinical Pharmacy.

Sean Sullivan, JD, is cofounder, president, and chief executive officer (CEO), Institute for Health and Productivity Management (IHPM), and CEO, Initiative for Value-Based Health Benefits. Before founding IHPM, Sullivan was the original president and CEO, National Business Coalition on Health. He also spent 10 years as a Washington-based health policy analyst-as a fellow, American Enterprise Institute for Public Policy Research, and as executive vice president, New Directions for Policy. He is the author of articles and monographs on health policy and health care market trends and has testified on these subjects before the U.S. Congress and state legislatures. Sullivan is editorin-chief of the quarterly magazine Health $\&$ Productivity Management, and is on the editorial board of Managed Healthcare Executive. He also serves on the National Advisory Board of the Corporate Health Improvement Program. Sullivan speaks nationally and internationally on health and productivity management as a leading business strategy for the modern knowledge-based economy.

Sullivan holds degrees in economics from Harvard University and in law from Stanford University. 


\section{Table of Contents}

\section{Managed Care to Medicare: Sharing the Burden of Chronic Kidney Disease}

S2 Introduction: Chronic Kidney Disease: A Burgeoning Health Epidemic

Wendy L. St. Peter, PharmD, FASN, FCCP, BCPS

S6 Disease Progression and the Application of Evidence-Based Treatment Guidelines Diagnose It Early: A Case for Screening and Appropriate Management Harold J. Manley, PharmD, FASN, FCCP, BCPS

S13 Chronic Kidney Disease and Medicare Wendy St. Peter, PharmD, FASN, FCCP, BCPS

\section{S19 Employer Challenges With the Chronic Kidney Disease Population} Sean Sullivan, JD

S22 Continuing Education*: CE Submission Instructions and Posttest Worksheet

\section{Target Audience}

Physicians and pharmacists practicing in a managed care setting

\section{Learning Objectives}

After completing this activity, the participant should be better able to

1. appreciate that chronic kidney disease (CKD) is common and care is costly and suboptimal;

2. discuss treatment strategies to reduce progression of CKD and to manage comorbidities;

3. understand the managed care perspective of CKD;

4. recognize challenges that employers face when employees develop CKD; and

5. define barriers for CKD patients under Medicare Part D.

This supplement was funded by an educational grant from Amgen, Inc. Articles in this supplement are based on the proceedings of a symposium held at the Academy of Managed Care Pharmacy's 19th Annual Meeting and Showcase on April 11, 2007, in San Diego, California. The symposium was supported by an educational grant from Amgen, Inc.

This program will educate managed care professionals and health care providers about CKD patient care. The program will provide a review of the current guidelines for diagnosis and treatment of CKD, discuss the risks of comorbidities (e.g., hypertension, diabetes, anemia), and identify potential patient barriers of Medicare Part D. Non-Medicare Part D payers and providers will learn the impact of CKD in their respective populations and the importance of early screening and detection of the disorder.

*A total of 0.15 CEUs ( 1.5 contact hours) will be awarded for successful completion of this continuing education program (ACPE \#245-999-07-109-H04-P) and 1.5 AMA PRA Category 1 Credits. For faculty disclosures, please see pages S4, S12, S17, and S21. For accreditation information, please see page S22.

The content and views presented in this article are those of the faculty/authors and do not necessarily represent the official policies or views of the Academy of Managed Care Pharmacy, the authors' institutions, the continuing medical education grantor, or Amgen, Inc., respectively. The authors have disclosed if any unlabeled use of products is mentioned in their articles. Before prescribing any medication, clinicians should consult primary references of full prescribing information.

Since this educational program was presented, the U.S. Food and Drug Administration has released guidance for health care professionals and label changes for the erythropoiesis-stimulating agents that recommend treating hemoglobin levels to $<12 \mathrm{~g}$ per dL in cancer patients and to a target range of 10 to $12 \mathrm{~g}$ per dL in chronic kidney disease patients. U.S. Food and Drug Administration. FDA Strengthens Boxed Warnings, Approves Other Safety Labeling Changes for Erythropoiesis-Stimulating Agents (ESAs). November 8, 2007. Available at: www.fda.gov/bbs/topics/NEWS/2007/NEW01740.html. 


\title{
Introduction: Chronic Kidney Disease: A Burgeoning Health Epidemic
}

\author{
Wendy L. St. Peter, PharmD, FASN, FCCP, BCPS
}

\begin{abstract}
BACKGROUND: The kidneys function as excretory, biosynthetic, and metabolic organs, vital for maintaining normal physiology. Although dialysis can replace some kidney functions, it cannot replicate the biosynthetic and metabolic activities of the normal kidney. Chronic kidney disease (CKD) and its terminal complication, end-stage renal disease (ESRD), may progress undetected until immediately before symptomatic kidney failure develops. At this point in the disease process, few opportunities exist to prevent adverse outcomes.
\end{abstract}

OBJECTIVES: To (1) review the incidence, prevalence, and staging of CKD and ESRD and (2) elucidate that the management of CKD is suboptimal and costly.

SUMMARY: CKD is defined according to the presence or absence of kidney damage and level of kidney function. The Kidney Disease Outcomes Quality Initiative designates 5 stages of CKD, with stage 5 being ESRD-the point at which patients' loss of kidney function precipitates a need for dialysis or kidney transplant. The United States Renal Data System has documented monumental growth of the ESRD population and its significant impact on Medicare and its budget. In 2005, approximately $1.2 \%$ of Medicare's 31 million beneficiaries who had ESRD generated $6.4 \%$ of Medicare's total costs. One of the most important aspects of CKD diagnosis and treatment is early detection and aggressive management of underlying causes. However, care for CKD patients is fragmented. Primary care physicians, cardiovascular specialists, endocrinologists, dietitians, and pharmacists may be engaged in the patient's care early but the nephrologist may not be approached until late, if at all.

CONCLUSION: CKD is costly. Preventing progression to ESRD may improve quality of life and help save health care dollars. A concerted approach to manage CKD patients effectively starts with early detection and integrated management by multiple specialties. Delaying disease progression is crucial and must include patient education and aggressive treatment and management of CKD and its comorbidities. Interdisciplinary care models in which pharmacists are integrally involved should be replicated.

J Manag Care Pharm. 2007:13(9):S2-S5

Copyright@ 2007, Academy of Managed Care Pharmacy. All rights reserved.

\section{Author}

WENDY L. ST. PETER, PharmD, FASN, FCCP, BCPS, is an associate professor, Department of Pharmaceutical Care and Health Systems, College of Pharmacy at the University of Minnesota, Minneapolis. She is also an investigator with the Chronic Disease Research Group and the United States Renal Data System.

AUTHOR CORRESPONDENCE: Wendy L. St. Peter, PharmD, Associate Professor, College of Pharmacy at the University of Minnesota, 914 S. 8th St., Suite D-206, Minneapolis, MN 55404. Tel.: 612.347.7752; Fax: 612.347.5878; E-mail:WStPeter@nephrology.org
I $\mathrm{n}$ the normal person, the kidneys, weighing about 4 ounces each, process about 200 liters of blood daily to remove waste products and excess water. They metabolize 25-hydroxyvitamin $\mathrm{D}$ to active 1,25 dihydroxy-vitamin D (calcitriol), which regulates absorption of calcium from foods and affects bone formation. Kidneys are critical to erythropoietin formation, which stimulates red blood cell production. They also regulate renin, which regulates blood volume and blood pressure. The kidneys function as excretory, biosynthetic, and metabolic organs, vital for maintaining normal physiology. Although dialysis can replace some kidney functions, it cannot replicate the biosynthetic and metabolic activities of the normal kidney.

\section{CKD and Risk Factors}

In the United States, about 1 in 9 adults has chronic kidney disease (CKD) and a minority suffer from its terminal complication, end-stage renal disease (ESRD). ${ }^{1,2}$ CKD is usually silent until its late stages, and without aggressive screening, detection may not occur until immediately before symptomatic kidney failure develops. At this point in the disease process, few opportunities exist to prevent adverse outcomes, such as further decline in kidney function necessitating dialysis, cardiovascular complications, shortened lifespan, and poor quality of life. The Kidney Early Evaluation Program (KEEP) is a national CKD screening program supported by the National Kidney Foundation (NKF) to identify patients at risk of developing CKD. The NKF organizes KEEP from its central offices, but the program is conducted in most states through NKF affiliates by a cadre of volunteer health professionals. Patients learn about KEEP in many ways; they may be referred by a health care provider or may learn about the program through the NKF's outreach efforts in the lay literature and poster campaigns.

Patients at higher risk for CKD include patients with diabetes, hypertension, or a family history of hypertension, diabetes, or CKD. CKD appears more often in minority groups; black American, Native American, Hispanic, Asian, and Pacific Islander populations are at higher risk of developing CKD than are white Americans. In these populations, diabetes and hypertension, which are the predominant causes of ESRD, are more common and tend to be familial. ${ }^{1,2}$ Patients who have a family history of those disorders or CKD are also at risk for developing CKD.

Until 2002, a common staging system for CKD did not exist and numerous terms were used to describe it. In 2002, the NKF Kidney Disease Outcomes Quality Initiative (KDOQI) Work Group developed a staging system (see Table). CKD is now defined according to the presence or absence of kidney damage and level of kidney function-regardless of the patient's underlying diagnosis. KDOQI designates 5 stages, with stage 5 being ESRD, when loss of kidney function (a glomerular filtration rate $[G F R]<15 \mathrm{~mL}$ per minute per $1.73 \mathrm{~m}^{2}$ ) precipitates 
a need for dialysis or kidney transplant. Patients in stages 1 and 2 may have robust, normal, or slightly lowered GFR with evidence of underlying kidney damage, including proteinuria; large or small kidneys on an ultrasound; or other evidence of compromised function. All people with GFR $<60 \mathrm{~mL}$ per minute per $1.73 \mathrm{~m}^{2}$ for more than 3 months are classified as having CKD. This classification represents a loss of $50 \%$ or more of the adult level of normal kidney function. ${ }^{1}$ Additionally, all people with kidney damage are classified as having CKD regardless of their GFR. ${ }^{1}$

Approximately 450,000 Americans are in stage 5 CKD, or ESRD. The majority of patients-almost 20 million-occupy the lower stages. Almost 6 million patients have stage 1, more than 5 million have stage 2, approximately 8 million have stage 3 , and 400,000 have stage 4 disease. Experts in the field now consider CKD epidemic and estimate another 20 million patients are at risk of developing CKD. ${ }^{1,2}$

Not all patients with CKD progress to the later stages of CKD or to ESRD because they die prematurely from other causes. ${ }^{3}$ CKD comorbidities, such as cardiovascular disease (CVD), contribute to the high death rate in CKD. Patients usually have numerous comorbidities; therefore, managing the whole patient becomes a major challenge for CKD health care teams. The patients who progress and survive to reach ESRD might be considered lucky, although they rarely feel that way.

\section{CKD Prevalence}

The United States Renal Data System (USRDS) uses data from the Centers for Medicare \& Medicaid Services (CMS) and other databases to provide information about CKD patients. Since 1990, the number of patients newly diagnosed with ESRD has increased from slightly less than 50,000 to more than 102,000 in 2005. ${ }^{3}$ The number of ongoing ESRD patients has also increased, from approximately 186,000 in 1990 to nearly 485,000 in 2005..$^{3}$ Although the rate of new ESRD cases has been slowing, a recent prediction model estimates that there will be more than 785,000 ESRD patients in the United States by $2010 .{ }^{3}$

\section{CKD Costs}

In 2005, approximately $1.2 \%$ of Medicare's 31 million beneficiaries had ESRD. This small part of the Medicare population generates a disproportionate share-6.4\% — of Medicare's total costs. $^{3}$ The Figure charts Medicare and employer group health plan (EGHP) ESRD spending for people less than 65 years old. The Figure (left side) shows that in the United States, about $\$ 32$ billion was spent on ESRD care in 2004, with about $\$ 20$ billion being the expense of Medicare and Medicare patients. ${ }^{3}$ The remainder is non-Medicare spending. Data from the Thomson-Medstat database, which includes approximately 4 million lives from roughly 100 EGHPs (Figure, right side), indicate that EGHP costs are also rising drastically. ${ }^{3}$

\section{TABLE Stages of CKD}

\begin{tabular}{l|l|l}
\hline Stage & \multicolumn{1}{|c|}{ Description } & $\begin{array}{c}\text { GFR }(\mathrm{mL} \text { per minute } \\
\left.\text { per } 1.73 \mathrm{~m}^{2}\right)\end{array}$ \\
\hline 1 & $\begin{array}{l}\text { Kidney damage* with normal or } \\
\text { increased GFR }\end{array}$ & $>90$ \\
\hline 2 & $\begin{array}{l}\text { Kidney damage* with mildly decreased } \\
\text { GFR }\end{array}$ & $60-89$ \\
\hline 3 & Moderately decreased GFR & $30-59$ \\
\hline 5 & Severely decreased GFR & $15-29$ \\
\hline
\end{tabular}

* Kidney damage is defined as pathologic abnormalities or markers of damage, including abnormalities in blood or urine tests or imaging studies.

Adapted from K/DOQI Clinical Practice Guidelines on Hypertension and Antihypertensive Agents in Chronic Kidney Disease. Available at: www.kidney.org/ professionals/kdoqi/guidelines_bp/executive_summary.htm\#table2. Accessed September 19, 2007.

$C K D=$ chronic kidney disease $; G R=$ glomerular filtration rate.

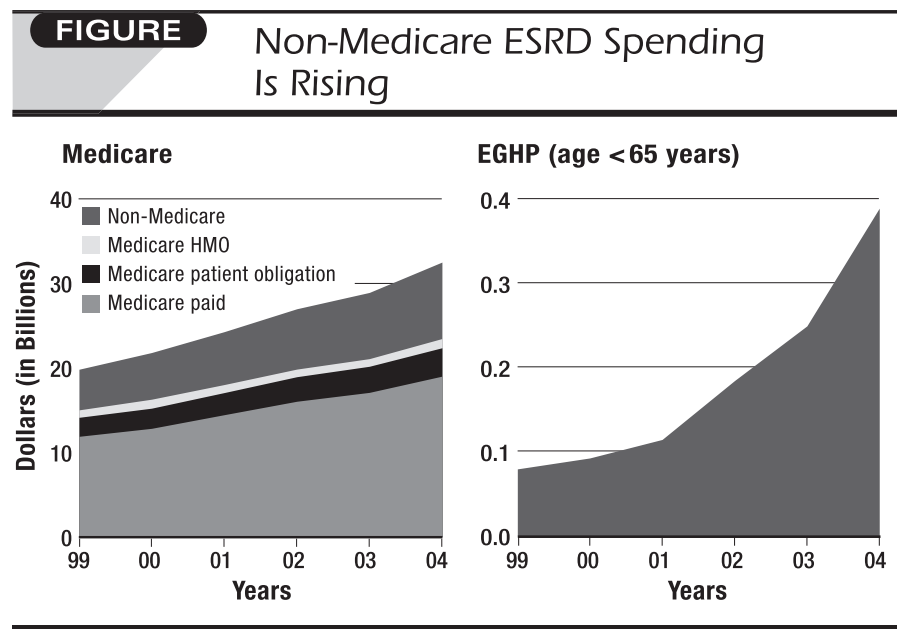

United States Renal Data System. USRDS 2006 Annual Data Report: Atlas of End-Stage Renal Disease in the United States. Bethesda, MD: National Institutes of Health, National Institute of Diabetes and Digestive and Kidney Diseases; 2006. $E G H P=$ employer group health plan; $E S R D=$ end-stage renal disease;

$\mathrm{HMO}=$ health maintenance organization.

CKD care is costly. Researchers have tracked economic costs of CKD and its transition to ESRD. Some of these findings show that after patients begin dialysis, costs spike to about $\$ 70,000$ annually. Dialysis costs have been stable at $\$ 1,000$ per patient per month since the early 1990s. ${ }^{3}$ Although many of the drugs used to treat CKD are inexpensive, medication costs have increased as new agents have been developed to treat the complications of CKD. Some of these newer and more expensive therapies include erythropoietin-stimulating agents, intravenous iron, intravenous vitamin D, and phosphate binders. ${ }^{3}$ Transplant patients are even more costly, with associated medical costs of about $\$ 102,000$, on average, in the year of transplant. ${ }^{3,4}$ One 
could hypothesize that identifying CKD patients early and preventing progression to ESRD might improve quality of life and save health care dollars. ${ }^{5}$

\section{A Problem: Fragmented Care}

A CKD patient has several affected organ systems in addition to the renal system. Cardiovascular system involvement (i.e., electrolytes, lipids, and blood pressure); diabetes management; and dietary restrictions require that many different practice areas be involved in the care of a CKD patient. While the primary care physician may play a role in care coordination, dieticians, nephrologists, endocrinologists, and cardiologists are essential when addressing the many interacting disorders. Without interdisciplinary communication, care for patients may become fragmented. ${ }^{5}$ Their education, too, suffers, as they are prevented from being involved in their own care. ${ }^{5}$

Care fragmentation delays CKD detection, preventing early use of evidence-based management principles like early screening and aggressive adherence to treatment guidelines to stop progression and to manage underlying comorbidities (e.g., anemia, hypertension, CVD, diabetes, malnutrition, and bone disease). An example of an area that is subject to fragmented care is vascular access for dialysis patients. Temporary vascular access, as opposed to the more appropriate permanent arteriovenous fistula, at the first dialysis visit is common but is detrimental and usually avoidable. In dialysis, a normal vein cannot accommodate the volume and rate of blood withdrawal that occurs during hemodialysis (blood is returned to the patient after purification). A surgeon sews an artery and vein in the arm together to create a fistula, and arterial pressure eventually enlarges the vein so it can accommodate a large needle for dialysis. Patients referred early to a nephrologist are more likely to have better blood pressure control, less risk for pulmonary edema, and acceptable arteriovenous fistula.

Treating comorbidities and modifying risk factors is an interdisciplinary challenge. Early detection, aggressive management, and patient education are critical to preventing CKD progression. For optimal benefits, health care professionals need a concerted approach to manage CKD patients effectively. Health care providers must involve and educate patients from the moment they are diagnosed, empowering them to make informed decisions with their health care team. Delaying progression is crucial and must include aggressive blood pressure control using angiotensin-converting enzyme inhibitors (ACEIs) or angiotensin II receptor blockers (ARBs) and optimal diabetes management. ${ }^{5}$ It is imperative that complications-anemia, malnutrition, bone and mineral metabolism disorders, calcification, and acidosis-are prevented and that smoking cessation is aggressively promoted. When indicated, the team will need to refer the patient to a nephrologist to either initiate dialysis or have a kidney transplant. These areas represent opportunity for pharmacist involvement. ${ }^{5,6}$

\section{Pharmacist Involvement: Possibilities}

CKD is epidemic and under-diagnosed. Management principles are under-used and cost is high. Numerous opportunities exist for managed care and clinical pharmacists. Pharmacists can organize screening programs for their patient population(s) using tools available through KEEP. Once patients are identified, they need to be referred to an appropriate health care provider for evaluation and management.

Managed care pharmacists can develop medication therapy management protocols to ensure that CKD patients are initiated on ACEIs or ARBs to reduce rate of kidney disease progression. They can work to ensure that comorbidities such as hypertension, diabetes, anemia, and bone and mineral metabolism disorders are appropriately evaluated and managed. Managed care pharmacists can develop educational materials for CKD patients that focus on the above issues. Pharmacists who work in health maintenance organizations can also work directly with patients. For example, at Kaiser Permanente's Southern California locations, pharmacists monitor serum creatinine. If a patient's serum creatinine is elevated more than once, pharmacists examine the patient's medical history and can refer the patient appropriately to a nephrologist, primary care practitioner, social worker, or dietician. Multidisciplinary CKD clinics in Canada often have access to pharmacists under their government health care plan. ${ }^{7}$ Some U.S. pharmacists are integrally involved in providing CKD care. ${ }^{8}$

Ideally, these models will become ubiquitous. Comprehensive, coordinated, collaborative health care must eliminate barriers and employ measurable quality indicators to improve patient outcomes.

\section{DISCLOSURES}

Author Wendy L. St. Peter discloses that she receives grant/research support from Amgen, Inc. and GenZyme Corporation.

\section{REFERENCES}

1. National Kidney Foundation. K/DOQI clinical practice guidelines for chronic kidney disease: evaluation, classification, and stratification. Available at: www.googlesyndicatedsearch.com/u/kidney?q=Clinical+Practice+Guidelines \&sa.x=0\&sa.y=0\&sa=Go. Accessed August 25, 2007.

2. Coresh J, Astor BC, Greene T, Eknoyan G, Levey AS. Prevalence of chronic kidney disease and decreased kidney function in the adult U.S. population: Third National Health and Nutrition Examination Survey. Am J Kidney Dis. 2003;41:1-12

3. The United States Renal Data System. The United States Renal Data System Annual Data Report 2007. Available at: www.usrds.org/adr.htm. Accessed September 25, 2007.

4. St. Peter WL, Khan SS, Ebben JP, Pereira BJG, Collins AJ. Chronic kidney disease: the distribution of health care dollars. Kidney Int. 2004;66:313-21.

5. St. Peter WL, Schoolwerth AC, McGowan T, McClellan WM. Chronic kidney disease: issues and establishing programs and clinics for improved patient outcomes. Am J Kidney Dis. 2003;41:903-24. 
6. Pereira BJ. Optimization of pre-ESRD care: the key to improved dialysis outcomes. Kidney Int. 2000;57:351-65.

7. Mendelssohn DC, Toffelmire EB, Levin A. Attitudes of Canadian nephrologists toward multidisciplinary team-based CKD clinic care. Am J Kidney Dis. 2006; $47: 277-84$
8. Joy MS, Candiani C, Vaillancourt BA, Chin H, Hogan SL, Falk RJ. Reengineering clinical operations in a medical practice to optimize the management of anemia of chronic kidney disease. Pharmacotherapy. 2007;27(5):734-44. 


\title{
Disease Progression and the Application of Evidence-Based Treatment Guidelines Diagnose It Early: A Case for Screening and Appropriate Management
}

\author{
Harold J. Manley, PharmD, FASN, FCCP, BCPS
}

\begin{abstract}
BACKGROUND: Screening processes to identify patients who have chronic kidney disease (CKD) early in the disease allow time to manage its comorbidities and complications effectively and aggressively. The Kidney Early Evaluation Program (KEEP), sponsored by the National Kidney Foundation (NKF), is a free screening program that targets people who have diabetes, hypertension, and parents, grandparents, or siblings with diabetes, hypertension, or CKD.

OBJECTIVES: To (1) introduce KEEP and its objectives and (2) review population data and progress with goals to date.

SUMMARY: The KEEP goals are to raise awareness of CKD, especially in high-risk patients, provide free testing, and encourage dialogue between patients and their physicians, leading to a treatment plan. Of the 55,000 patients who have been screened through KEEP, approximately $13,000(29 \%)$, or nearly 1 in 3 patients, have been identified as having CKD. Once a patient has been diagnosed with CKD, clinicians must address risk factors such as diabetes, hypertension, and kidney-specific diseases (e.g., glomerular diseases) that contribute to the process of renal decline. The NKF through the Kidney Disease Outcomes Quality Initiative has assembled a series of guidelines addressing dialysis adequacy, vascular access, anemia, nutrition, CKD, bone and mineral metabolism, dyslipidemia, hypertension, cardiovascular disease, and diabetes.

CONCLUSION: CKD is quite common but often unrecognized and undertreated, even though rigorous guidelines for diagnosis and care have been developed. Ten areas have been identified as important for optimal care of the CKD patient. Each of these areas should be addressed and closely monitored in this population: hypertension, anemia, glucose control, lipid control, smoking cessation, aspirin prophylaxis and use of a beta-blocker post-myocardial infarction, use of angiotensin-converting enzyme inhibitors or angiotensin II receptor blockers, diet, exercise, and weight control.
\end{abstract}

J Manag Care Pharm. 2007:13(9):S6-S12

Copyright $\odot$ 2007, Academy of Managed Care Pharmacy. All rights reserved.

\section{Author}

HAROLD J. MANLEY, PharmD, FASN, FCCP, BCPS, is director, clinical pharmacy, VillageHealth Disease Management, Glenmont, New York.

AUTHOR CORRESPONDENCE: Harold J. Manley, PharmD,

Director, Clinical Pharmacy, VillageHealth Disease Management, 16 Vagele Lane, Glenmont, NY 12077. Tel.: 518.932.4416;

E-mail: harold.manley@villagehealth.com
The Kidney Early Evaluation Program (KEEP), sponsored by the National Kidney Foundation (NKF), is a free screening program that targets people who have diabetes, high blood pressure, and parents, grandparents, or siblings with diabetes, hypertension, or chronic kidney disease (CKD). ${ }^{1}$ Patients can refer themselves after learning about KEEP from magazines, newspaper articles, or other media, or can be referred by a health care provider. Although KEEP is administered by the NKF, the actual screening events are organized by $52 \mathrm{NKF}$ affiliates. KEEP is staffed by lay and professional volunteers who are trained by the NKF. The program's goals are to raise awareness of CKD, especially in highrisk patients; provide free testing; and encourage dialogue between patients and their physicians, leading to a treatment plan. Educating and empowering patients is also a goal in order to prevent or delay CKD, initiate appropriate referrals for follow-up care, and provide ongoing information and support. ${ }^{1}$

During a KEEP screening, volunteer health care professionals (e.g., physicians, nurses, and pharmacists) monitor blood pressure, record weight, and coordinate lab work (e.g., blood glucose, hemoglobin, urine dipstick for microalbuminemia and hematuria, albumin, and serum creatinine). Albumin to creatinine ratio is employed to determine serum creatinine and estimate glomerular filtration rate (eGFR) using a Modification of Diet in Renal Disease equation. Clinicians notify patients of the screening results and may refer them to their primary care physicians for follow-up if abnormal results were identified.

Abnormal results identified during a KEEP screening are not considered diagnostic but rather, indicative of increased risk. Overall, patient participation in the KEEP screening process takes approximately 30 minutes. At the conclusion of the screening, the clinician sends data collected to the NKF. ${ }^{1}$ Aggregate data are published yearly in the KEEP Annual Data Report. Of the 55,000 patients who have been screened through the KEEP process since its inception in 2000, approximately 13,000 (29\%), or nearly 1 in 3 patients, have been identified as having CKD, with stage 3 being identified most frequently. ${ }^{2}$

\section{CKD: Progression and Comorbidities}

Once a patient has been diagnosed with CKD, clinicians must identify and address risk factors associated with disease progression. Risk factors may be divided into 3 descriptive categories:

1. Susceptibility factors, such as advanced age, racial/ethnic minorities, family history, and low income or education, may put a patient at an increased risk of developing CKD. For example, approximately 50 million Americans are more than 60 years old and should be monitored for progressive renal function decline. ${ }^{2}$ Thirty-four million black Americans and 35 million Hispanics or Latinos are also at increased risk for CKD. ${ }^{2}$ 


\section{Disease Progression and the Application of Evidence-Based Treatment Guidelines}

Diagnose It Early: A Case for Screening and Appropriate Management

2. Initiators are factors such as diabetes, hypertension, and kidney-specific diseases (e.g., glomerular diseases) that are strongly associated with the beginning of renal decline.

3. Progression factors contribute to the advancement of CKD and include hyperglycemia, hypertension, proteinuria, and smoking. ${ }^{2}$ Each of these factors is modifiable through patient behaviors and drug therapy. Addressing them is critical. Diabetes is the primary cause of end-stage renal disease (ESRD). However, the presence of hypertension is also a strong risk factor and is more common, affecting 43 million Americans. ${ }^{2}$ Most often, diabetes and hypertension are comorbid and must both be addressed and managed.

Evaluation includes diagnosing the underlying cause of $\mathrm{CKD}$, staging for severity, identifying comorbid conditions and complications, and assessing risk of cardiovascular disease (CVD). The results of evaluation should drive specific therapy (see Table 1) with an overall goal of preventing further loss of kidney function. Glomerular disease should be treated, if possible, and if diabetes and/or hypertension are present, controlling glycosylated hemoglobin (Alc) and blood pressure is crucial. Early detection and aggressive management of CKD and its comorbidities may slow or arrest progression to ESRD. Employing medications that may reduce glucose or blood pressure and simultaneously reduce proteinuria; prescribing an erythropoiesis-stimulating agent (ESA) and/or an iron product for anemia; starting a lipid-lowering product; and using primary prevention medications such as aspirin are part of the CKD management principles.

Medication review is critical for patients who have CKD. There are several areas where patients require guidance or where medications require adjustment. Renally cleared medications often require dosage adjustment as kidneys fail and some medications accumulate, making them more difficult to use. It may be necessary to increase therapeutic drug monitoring and a host of new medications may need to be added. New medications added as renal decline progresses must be compatible with the current regimen. A patient with stage 3 or 4 CKD is prescribed an average of 6 to 8 medications. ${ }^{3} \mathrm{~A}$ patient at end-stage CKD is prescribed about 10 to 12 medications. ${ }^{4}$ Therapeutic drug monitoring should prevent most drug-drug interactions and some adverse drug events, while patient education may help to make adverse events more manageable for the patient and provide continual encouragement for patient adherence to the treatment regimen.

\section{Kidney Disease Outcomes Quality Initiative Guidelines}

The CKD patient population tends to experience a number of adverse outcomes and comorbidities, and the NKF has attempted to help clinicians address these concerns. The Kidney Disease Outcomes Quality Initiative (KDOQI), developed by a multidisciplinary team, was created to provide comprehensive diagnosis and management guidelines for CKD. ${ }^{5}$ Within

\section{TABLE $1 \longdiv { \text { Management Principles for CKD } }$}

\begin{tabular}{|c|c|}
\hline $\begin{array}{l}\text { Delay or } \\
\text { stop CKD } \\
\text { progression }\end{array}$ & $\begin{array}{l}\text { - Treat underlying conditions if possible. } \\
\text { - Address blood pressure control, aggressively targeting } \\
\text { JNC 7's target values. } \\
\text { - Use ACEIs as tolerated, monitoring for renal } \\
\text { deterioration and hyperkalemia. } \\
\text { - Follow the American Diabetes Association } \\
\text { recommendations for glycemic control (target Alc <7\%). } \\
\text { - Consider protein restriction. } \\
\text { - Treat hyperlipidemia. } \\
\text { - Avoid nephrotoxins (nonsteroidal anti-inflammatory } \\
\text { agents, aminoglycosides). }\end{array}$ \\
\hline $\begin{array}{l}\text { Treat CKD's } \\
\text { pathologic } \\
\text { manifestations }\end{array}$ & $\begin{array}{l}\text { - Anemia (erythropoietin-stimulating agents) } \\
\text { - Hyperphosphatemia (dietary phosphate binders and } \\
\text { dietary phosphate restriction) } \\
\text { - Hypocalcemia (calcium supplements and/or calcitriol) } \\
\text { - Hyperparathyroidism (calcitriol or vitamin D analogs) } \\
\text { - Volume overload (loop diuretics or ultrafiltration) } \\
\text { - Metabolic acidosis (oral alkali supplementation) } \\
\text { - Uremic manifestations with chronic renal replacement } \\
\text { therapy (hemodialysis, peritoneal dialysis, or renal } \\
\text { transplantation) } \\
\text { - Cardiovascular complications using standard of care }\end{array}$ \\
\hline $\begin{array}{l}\text { Plan for } \\
\text { chronic renal } \\
\text { replacement } \\
\text { therapy }\end{array}$ & $\begin{array}{l}\text { - Educate patients early and frequently about disease } \\
\text { progression, potential dialysis modalities, renal } \\
\text { transplantation, and the option to refuse or discontinue } \\
\text { chronic dialysis. } \\
\text { - Place permanent vascular access (arteriovenous fistula) } \\
\text { at least } 6 \text { months in advance of anticipated date of } \\
\text { dialysis. } \\
\text { - Arrange elective peritoneal dialysis catheter insertion. } \\
\text { - Refer for renal transplantation early. }\end{array}$ \\
\hline $\begin{array}{l}\text { Establish } \\
\text { a multi- } \\
\text { disciplinary } \\
\text { team early }\end{array}$ & $\begin{array}{l}\text { - Refer to nephrology early. } \\
\text { - Involve a renal dietitian. } \\
\text { - Schedule vascular surgery for permanent vascular } \\
\text { access. } \\
\text { - Schedule general surgery for peritoneal catheter } \\
\text { placement. } \\
\text { - Enroll the patient in a renal transplant center. }\end{array}$ \\
\hline $\begin{array}{l}\text { Address } \\
\text { dietary } \\
\text { changes }\end{array}$ & $\begin{array}{l}\text { - Restrict protein as the patient approaches CKD stage } 5 \text { to } \\
\text { delay onset of uremic symptoms. } \\
\text { - Assess malnutrition risk and implement strategies } \\
\text { to correct or address it. } \\
\text { - Restrict phosphate, starting early in CKD. } \\
\text { - Restrict potassium. } \\
\text { - Restrict sodium and water as necessary to avoid } \\
\text { volume overload. }\end{array}$ \\
\hline
\end{tabular}

References 1 through 9 were used to develop this chart.

$A C E I=$ angiotensin-converting enzyme inhibitor; $C K D=$ chronic kidney disease;

JNC $7=$ Seventh Report of the Joint National Committee on Prevention, Detection, Evaluation, and Treatment of High Blood Pressure. 


\section{FIGURE 1 Association of Level of GFR With Complications}

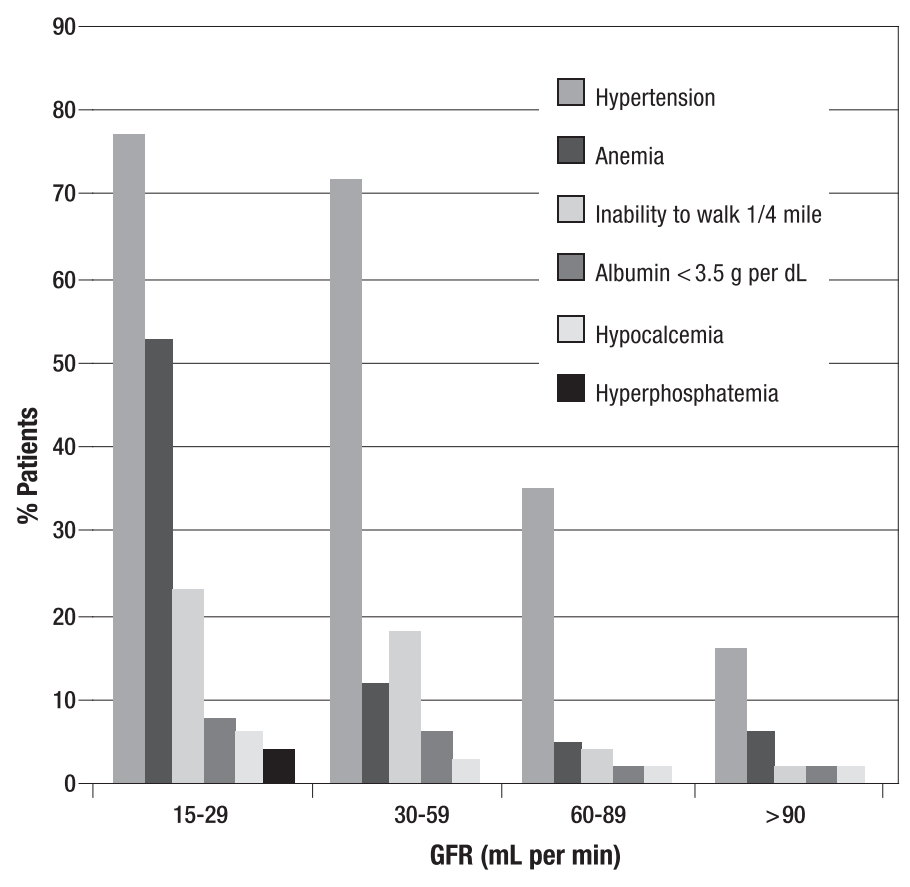

Adapted from K/DOQI Clinical Practice Guidelines for Chronic Kidney Disease Evaluation, Classification, and Stratification. Available at: www.kidney.org/ professionals/KDOQI/guidelines_ckd/toc.htm. Accessed on September 17, 2007. GFR=glomerular filtration rate

KDOQI, separate guidelines have been developed to address each of the following areas: dialysis adequacy, vascular access, anemia, nutrition, CKD, bone and mineral metabolism, dyslipidemia, hypertension, CVD, and diabetes. ${ }^{1}$ Although these diagnoses must be addressed in concert, each requires some specialized knowledge on the part of the clinician.

\section{Glomerular Filtration Rate}

Glomerular filtration rate (GFR), calculated from blood creatinine, age, race, gender, and other factors, is the best test measure to determine the degree of kidney dysfunction. A declining GFR is associated with additional complications, including anemia, inability to walk a quarter of a mile, low albumin (malnourishment), and electrolyte abnormalities (hypocalcemia and/or hyperphosphatemia) ${ }^{2}$ (Figure 1).

\section{Cardiovascular Disease}

Analysis of the Kaiser Permanente database has found that death rate correlates with declining GFR. ${ }^{6}$ Cardiovascular morbidity and mortality is greater among CKD patients than in the general population, and most patients with CKD will die of CVD before reaching ESRD. A 1999 study by Sarnak and Levey determined that the dialysis population, compared with the general population of people without $\mathrm{CKD}$, experiences a greater annual mortality rate related to cardiovascular events. ${ }^{7}$ In the general population, morbidity rates increase with age. For the dialysis population, risk is high from an early age and remains high. A 35- to 44-year-old dialysis patient, for example, has a cardiovascular risk comparable with that of an 84- or 85-year-old individual who is not on dialysis. CVD mortality rates are 15 times higher in the ESRD population than in people who do not have ESRD. All patients with CKD should be considered the highest risk group for CVD, and all CKD patients should undergo an assessment for traditional or CKD-related cardiovascular risk factors. Patients with CKD are at increased risk for CVD if they have traditional CVD risk factors, but additional risk factors specific to the CKD population can complicate their prognoses (Table 2).

The KDOQI treatment guidelines for CVD and hypertension emphasize that as GFR declines, the incidence of hypertension (defined as blood pressure $>140 / 90 \mathrm{~mm} \mathrm{Hg}$ ) increases from $42 \%$ in populations with normal GFR to approximately $75 \%$ in people with ESRD (GFR $<15 \mathrm{~mL}$ per minute per $1.73 \mathrm{~m}^{2}$ ). Bakris et al. conducted a meta-analysis examining mean arterial blood pressure and GFR decline. ${ }^{8}$ They found that as mean arterial blood pressure increases, GFR decline accelerates.

Reducing a blood pressure from $140 / 90 \mathrm{~mm} \mathrm{Hg}$ to 130/80 mm Hg can slow progressive renal disease. A blood pressure reduction of $10 \mathrm{~mm} \mathrm{Hg}$ can reduce renal disease progression by $65 \%$. For example, a 35 -year-old female with CKD and a serum creatinine of $1.5 \mathrm{mg}$ per $\mathrm{dL}$, an estimated GFR of $60 \mathrm{~mL}$ per minute per $1.73 \mathrm{~m}^{2}$, and a current blood pressure of 150/100 mg Hg could delay her progression to ESRD by 8 to 9 years by reducing blood pressure to $140 / 90 \mathrm{~mm} \mathrm{Hg}$. Further blood pressure reduction to 130/80 mm Hg could delay progression by 15 years. If, however, her blood pressure remains uncontrolled at 150/100 $\mathrm{mm} \mathrm{Hg}$, she can expect to need dialysis in 5 years. The importance of tight blood pressure control in CKD patients has also been identified by the Seventh Report of the Joint National Committee on Prevention, Detection, Evaluation, and Treatment of High Blood Pressure (JNC 7). ${ }^{9}$ This paradigm applies to all CKD patients in stages 1 through 4.

The average number of antihypertensive medications needed to control high blood pressure can be calculated, at least in the clinical setting, by looking at large antihypertensive trials. ${ }^{8,10}$ Most patients will require 3 or more medications to control blood pressure adequately. When choosing antihypertensive therapy for a patient with CKD, clinicians need to consider compelling comorbid indications, such as heart failure with systolic dysfunction, post-myocardial infarction with or without systolic dysfunction, chronic stable angina, high-risk coronary artery 
disease, recurrent stroke prevention, or supraventricular tachycardia. Depending on the comorbidities, certain antihypertensive medications are recommended for first-line use. Angiotensinconverting enzyme inhibitors (ACEIs) and angiotensin II receptor blockers (ARBs) are preferred in the diabetic and nondiabetic/ high protein excretion populations. No particular antihypertensive medication is preferred in the nondiabetic/low protein excretion and transplant populations. ${ }^{2}$ Both the KDOQI guidelines and JNC 7 recommend that clinicians prescribe the best agent for the patient's unique mix of comorbidities.

\section{Diabetes}

Diabetes, a CVD risk factor, also poses special challenges in the CKD patient. For each 1\% increase in Alc, the cardiovascular hazard ratio increases $15 \%$ in the patient with type 1 diabetes and $18 \%$ in the patient with type 2 diabetes. Three fourths of patients with diabetes die of CVD as opposed to one third of the general population. ${ }^{5}$ Steno et al. followed 160 type 2 diabetic patients with microalbuminuria for almost 8 years to determine if targeted, intensified, multifactorial intervention would lead to better outcomes than would conventional treatment. ${ }^{11}$ Study participants received either conventional therapy or intensive therapy. Intensive therapy stressed Alc control, employed aspirin therapy, and controlled lipids and blood pressure. In the intensive-therapy group, Alc values, systolic and diastolic blood pressure, serum cholesterol, and triglyceride levels were measured after an overnight fast. Findings included that the urinary albumin excretion rate declined to a greater extent than in the conventional-therapy group. Patients receiving intensive therapy reduced their risk of CVD by 53\%, nephropathy by $61 \%$, and retinopathy by $63 \%$. Target-driven, long-term, intensified intervention aimed at multiple risk factors in patients with type 2 diabetes and microalbuminuria reduces the incidence of $\mathrm{CKD}$ and prevents complications.

If a choice must be made between tight blood pressure control and tight glucose control in CKD patients, tight blood pressure control is more likely to reduce risk of stroke, any diabetic endpoint, diabetes mellitus death, or microvascular complications. ${ }^{8}$ Regardless, overall outcome will be better if all surrogate markers of CKD are addressed. ${ }^{7}$

\section{Anemia}

As kidney function declines during CKD progression from stage 1 to stage 5 , the risk of developing anemia increases dramatically (see Figure 2). ${ }^{12}$ Anemic patients with CKD usually have left ventricular hypertrophy, which may exacerbate heart failure. Furthermore, patients with CKD and anemia report reduced aerobic capacity, overall well-being, sexual function, and cognition. Body mechanisms, in attempting to fix or account for the damaged state caused by the triad of CKD, heart failure, and anemia, lead to a continuing promulgating cycle of worsening CKD, heart failure, and anemia. ${ }^{13}$

\section{TABLE 2 Traditional CVD Risk Factors and CKD-Specific CVD Risk Factors}

\begin{tabular}{l|l}
\hline Traditional CVD Risk Factors & CKD-Specific CVD Risk Factors \\
\hline Older age & Type of CKD \\
Male gender & Decreased GFR \\
White race & Proteinuria \\
Hypertension & RAS activity \\
Elevated LDL & ECF volume overload \\
Decreased HDL & Abnormal serum calcium \\
Diabetes mellitus & and phosphate \\
Tobacco use & Pronounced dyslipidemia \\
Physical inactivity & Anemia \\
Menopause & Malnutrition \\
Psychosocial stress & Inflammation \\
Family history of CVD & Infection \\
& Thrombogenic factors \\
& Elevated homocysteine \\
& Uremic toxins \\
\hline
\end{tabular}

National Kidney Foundation (2006). ${ }^{5}$

$C K D=$ chronic kidney disease $C V D=$ cardiovascular disease $E C F=$ extracellular fluid; GFR=glomerular filtration rate; $H D L=$ high-density lipoprotein;

$L D L=$ low-density lipoprotein; $R A S=$ renin-angiotensin system .

\section{FIGURE 2 Anemia Prevalence in CKD}

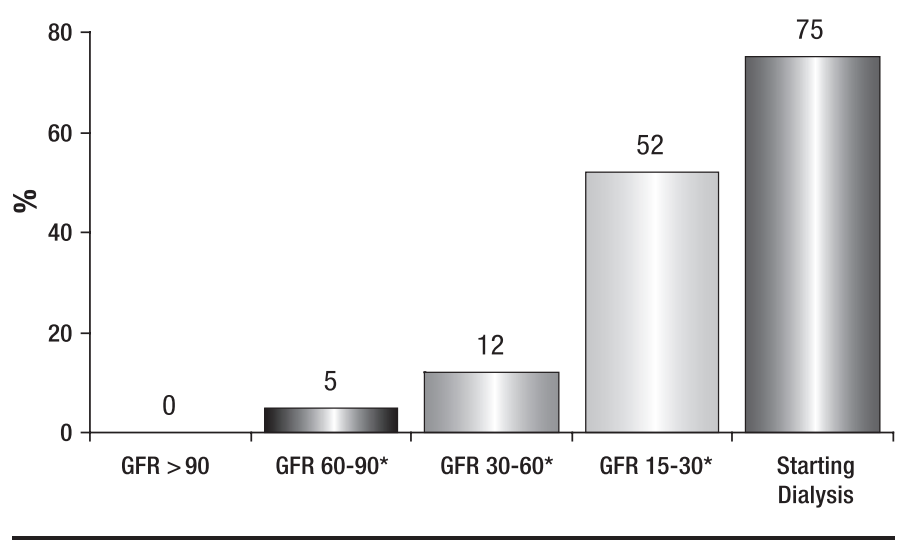

* Keane WF et al. ${ }^{12}$

** United States Renal Data System. USRDS 2005 Annual Data Report: Atlas of End-Stage Renal Disease in the United States. Bethesda, MD: National Institutes of Health, National Institute of Diabetes and Digestive and Kidney Diseases; 2005. $C K D=$ chronic kidney disease; $G F R=$ glomerular filtration rate.

The May 2006 KDOQI guidelines recommended a target hemoglobin of between 11 and $13 \mathrm{~g}$ per dL for anemia, but the April 2007 revision reduced the target range to 11 to $12 \mathrm{~g}$ per $\mathrm{dL} .{ }^{14}$ The KDOQI guidelines also recommend monitoring serum ferritin, transferrin saturation, and reticulocyte hemoglobin content for hemodialysis and peritoneal dialysis. To meet 


\section{Disease Progression and the Application of Evidence-Based Treatment Guidelines \\ Diagnose It Early: A Case for Screening and Appropriate Management}

KDOQI goals of a target hemoglobin of 11 to $12 \mathrm{~g}$ per dL, ESAs and oral or intravenous iron therapy are important pharmacologic therapies. ${ }^{15}$ With the recent black box warnings on ESAs emphasizing increased risk for death and serious cardiovascular reactions when administered to target a hemoglobin of $\geq 12$ g per $\mathrm{dL}$, dialysis organizations are examining their policies and adjusting algorithms.

In November 2006, 2 studies-CHOIR and CREATEwere published. The Correction of Anemia with Epoetin Alfa in Chronic Kidney Disease (CHOIR) included 1,432 patients with a mean GFR of $27 \mathrm{~mL}$ per minute per $1.73 \mathrm{~m}^{2} .{ }^{16}$ Of the study population, 715 patients were randomly assigned to receive a dose of epoetin alfa targeted to achieve a hemoglobin level of $13.5 \mathrm{~g}$ per $\mathrm{dL}$, and 717 received a dose targeted to achieve a level of $11.3 \mathrm{~g}$ per $\mathrm{dL}$. The groups attained average hemoglobin levels of $11.3 \mathrm{~g}$ per $\mathrm{dL}$ and $12.6 \mathrm{~g}$ per $\mathrm{dL}$, respectively, a difference of about $1 \mathrm{~g}$ per $\mathrm{dL}$, but the high-hemoglobin group required more erythropoietin to reach that level.

Two hundred twenty-two composite events occurred: 65 deaths (29.3\%), 101 hospitalizations for heart failure (45.5\%), 25 myocardial infarctions (11.3\%), and 23 strokes (10.4\%). Of these, 125 events occurred in the high-hemoglobin group and 97 events occurred in the low-hemoglobin group. Seven patients (3.2\%) were hospitalized for heart failure and myocardial infarction combined, and 1 patient $(0.5 \%)$ died after having a stroke. Improvements in quality of life were similar between the 2 groups. The probability of death was significantly less in the low-hemoglobin group. The use of a target hemoglobin level of $13.5 \mathrm{~g}$ per dL was associated with an increased risk of serious adverse events. ${ }^{16}$

Drueke et al. conducted a similar study, CREATE, (Cardiovascular Risk Reduction in Early Anemia Treatment with Epoetin Beta) to study whether correction of anemia in patients with stage 3 or 4 CKD improves cardiovascular outcomes. ${ }^{17}$ CKD patients with GFRs averaging $27 \mathrm{~mL}$ per minute per $1.73 \mathrm{~m}^{2}$ were randomized to ESA therapy to achieve a hemoglobin of 13 to $15 \mathrm{~g}$ per dL or 10.5 to $11.5 \mathrm{~g}$ per dL. Survival was similar between the groups over 48 months. One of the study conclusions was that early complete correction of anemia in CKD patients does not reduce the risk of cardiovascular events.

Other studies have examined hemoglobin's influence on outcomes. Besarab et al. studied more than 1,200 CKD patients receiving dialysis who were randomized to a normal hematocrit of $42+3 \%$ or a lower hematocrit of $30+3 \%$, equivalent to a hemoglobin of $12 \mathrm{~g}$ per $\mathrm{dL}$ and $10 \mathrm{~g}$ per $\mathrm{dL}$, respectively. ${ }^{18}$ After 29 months, patients in the normal-hematocrit group experienced 183 deaths and 19 first nonfatal myocardial infarctions. Those in the low-hematocrit group had 150 deaths and 14 nonfatal myocardial infarctions. The difference in event-free survival between the 2 groups did not reach the prespecified statistical stopping point, but the researchers halted the study early for safety concerns. Adequacy of dialysis declined for patients in the normal-hematocrit group, and they received more intravenous iron dextran than did low-hematocrit patients. The researchers concluded that hemodialysis patients with clinically evident heart failure or ischemic heart disease should be treated to lower hematocrit or hemoglobin targets.

In 2000, a KDOQI work group recommended targeting a hemoglobin concentration of 11 to $12 \mathrm{~g}$ per dL in CKD patients; they increased it to 11 to $13 \mathrm{~g}$ per $\mathrm{dL}$ in 2006. CHOIR and CREATE were published, suggesting that lower hemoglobins are safer than those exceeding approximately $12.6 \mathrm{~g}$ per $\mathrm{dL}$. Consequent to the U.S. Food and Drug Administration's requirement for a black box warning, the KDOQI work group reconvened and published revised guidelines in September 2007 stating, "In the opinion of the Work Group, in dialysis and non-dialysis patients with CKD receiving ESA therapy, the selected hemoglobin target should generally be in the range of 11 to 12 g per dL." 19

\section{Bone Disease Parameters}

KDOQI has also established targets for serum phosphorous, corrected calcium, the calcium-phosphorous product (a multiplication product of phosphorous and calcium levels), and intact parathyroid hormone in patients with CKD (Table 3). Once calcium-phosphorous product exceeds the reference range of between 40 and $45 \mathrm{mg}^{2}$ per $\mathrm{dL}^{2}$, the relative risk of death increases. Patients with secondary hyperparathyroidism or bone and mineral metabolism abnormalities often have bone pain, fractures, and joint pain and swelling. Their soft tissues may start to calcify and muscle weakness may occur. Pruritis, exacerbation or worsening of left ventricular hypertrophy, or worsening of anemia can also occur.

\section{Dyslipidemia}

Dyslipidemia is common in patients with CKD, and the lipid profile varies widely depending on the level of kidney function and the degree of proteinuria. All stages of CKD are considered a coronary heart disease (CHD) risk equivalent (similar to diabetes mellitus); therefore, all patients with CKD should be considered in the highest risk group for CHD. The common pattern of late-stage CKD includes hypertriglyceridemia, low or normal levels of low-density lipoprotein (LDL), low lipoprotein (a), and low high-density lipoprotein (HDL). KDOQI recommends initiating treatment when triglycerides exceed $>500 \mathrm{mg}$ per dL, LDL is $>100 \mathrm{mg}$ per dL, non-HDL > $130 \mathrm{mg}$ per dL, or HDL falls $<40 \mathrm{mg}$ per $\mathrm{dL}{ }^{5}$

Generally, HMG-CoA reductase agents (statins) are used to lower LDL; fibrates, including fenofibrates, are used to lower triglycerides; and niacin is used to increase HDL. In the CKD population, HMG-CoA reductase agents (statins) are preferred, with gemfibrozil and niacin used periodically. The complete NKF algorithm for treating dyslipidemia in CKD is available at www. kidney.org/professionals/kdoqi/guidelines_lipids/iii.htm\#Fig7. 


\section{Smoking}

In the CKD population, smoking confers a dose-dependent risk for CKD progression, with diabetic women at particular risk. After 20 years of smoking, males have 2.5 times the risk of $\mathrm{CKD}$, and women have 2.9 times greater risk than nonsmokers. ${ }^{20}$ Smoking represents one of the modifiable risk factors to improve patient outcomes in the CKD patient (Table 4).

\section{Progress Report}

Using Table 4 as a guide of optimal patient management, most patients are not managed to goal and there are many gaps to achieving optimal care. Among diabetics, only $7 \%$ of patients achieve their goals of Alc $<7$, a blood pressure $<130 / 80 \mathrm{~mm} \mathrm{Hg}$, and total cholesterol $<200 \mathrm{mg}$ per dL. ${ }^{21}$ Ninety-three percent of all patients have 1 or more of these risk factors for CKD development. One in 3 diabetics has hypertension, 1 in 2 has hyperlipidemia, and 1 in 6 is a smoker. ${ }^{21}$

ACEIs and ARBs are the cornerstone of hypertension therapy. They have been proven to slow kidney and CVD progression in diabetic populations specifically. Yet depending on the datasets employed to measure progress (e.g., National Health and Nutrition Examination Survey [NHANES] III or NHANES from 1999 to 2002), only 35\% to $37 \%$ of patients who should be prescribed an ACEI or an ARB (patients with diabetes, hypertension, or heart failure) actually receive these renal protective therapies. Underuse of ACEIs and ARBs is also an area that can be improved. ${ }^{22}$

Patients with comorbid CKD and diabetes should be taking a glucose-lowering agent (e.g., insulin, thiazolidinediones, secretagogues, or metformin). NHANES has been used for decades to assess nutritional status in the United States. Datasets from NHANES III (1988 to 1994) or NHANES (1999 to 2002) show clear differences in drug regimens between the CKD and non-CKD populations. For example, metformin use reported in NHANES is substantially less in CKD patients than in non-CKD patients ( $21 \%$ vs. $34 \%$ ), which may be attributed to metformin's propensity to cause lactic acidosis CKD. The manufacturer has recently tightened its recommendation for use of metformin in patients with kidney disease and states that patients whose serum creatinine concentrations exceed the upper limit of normal should not take metformin.

The United States Renal Data System (USRDS) 2007 Medstat dataset compares CKD and ESRD patients' adherence with a variety of drug regimens: ACEIs, ARBs, beta-blockers, statins, and secretagogues. Both CKD and ESRD populations show medication adherence rates of about $80 \%$ during the first 6 to 12 months after initiation. However, over the course of 2 years, medication adherence rates decrease steadily to $50 \%$. Patients who are in ESRD take, on average, 10 to 12 medications; CKD patients take 6 to 8 medications. Numerous factors contribute to nonadherence, but the number and timing of medications

\begin{tabular}{l|c|c}
\hline \multicolumn{1}{c}{ TABLE 3 } & \multicolumn{2}{c}{ KDOQl Targets } \\
for Bone Disease Parameters \\
\hline Parameter & \multicolumn{2}{c}{ Target } \\
\hline Serum P (mg per dL) & CKD Stages 3-4 & CKD Stage 5 \\
\hline Corrected serum Ca (mg per dL) & $\begin{array}{c}\text { Normal range for } \\
\text { laboratory used }\end{array}$ & $8.4-9.5$ \\
\hline Cax P product $\left(\mathrm{mg}^{2}\right.$ per dL $\left.\mathrm{dL}^{2}\right)$ & $<55$ & $<55$ \\
\hline $\begin{array}{l}\text { Intact parathyroid hormone } \\
\text { (pg per mL) }\end{array}$ & $\begin{array}{c}\text { Stage 3: 35-70 } \\
\text { Stage 4: 70-110 }\end{array}$ & $150-300$ \\
\hline
\end{tabular}

Adapted from K/DOQI Clinical Practice Guidelines for Bone Metabolism and Disease in Chronic Kidney Disease. Available at: www.kidney.org/professionals/ KDOQI/guidelines_bone/guide1.htm\#table14.

$\mathrm{Ca}=$ calcium; $\mathrm{CKD}=$ chronic kidney disease KDOQI=Kidney Disease Outcomes Quality Initiative; $P=$ phosphorus.

\section{TABLE $4 \longdiv { 1 0 \text { Steps to Success } }$}

\begin{tabular}{l|l}
\hline 1. & Hypertension control-130/80 mmHg \\
\hline 2. & Hemoglobin target-11-12 g per dL \\
\hline 3. & Glucose control_Alc $<7$ \\
\hline 4. & Lipid control_LDL-C $<100 \mathrm{mg}$ per dL, HDL-C $>40 \mathrm{mg}$ per dL \\
\hline 5. & Smoking cessation \\
\hline 6. & Aspirin + beta-blocker use post-myocardial infarction \\
\hline 7. & ACEI or ARB therapy \\
\hline 8. & Diet \\
\hline 9. & Exercise \\
\hline 10. & Weight control \\
\hline
\end{tabular}

$A C E I=$ angiotensin-converting enzyme inhibitor; $A R B=$ angiotensin II receptor blocker; HDL-C=high-density lipoprotein cholesterol; LDL-C=low-density lipoprotein cholesterol.

and the duration of treatment are 2 reasons that can decrease adherence significantly.

\section{Summary}

CKD is quite common but is often unrecognized and undertreated. Appropriate screening can identify patients at risk and facilitate early treatment for these patients. One program that has successfully screened patients and referred them for treatment is the NKF's KEEP. To date, more than 90,000 patients have been screened through KEEP, thanks in part to professional volunteers and a broad advertising campaign. When patients are identified as having $C K D$, this program helps link them with appropriate health care. Patients' specific health care plans should be guided by the NKF's KDOQI clinical practice guidelines, which recommend optimal management therapies for a variety of comorbid conditions to reduce complications in these patients. Early identification and aggressive treatment can prevent progression to ESRD. 


\section{DISCLOSURES}

Author Harold J. Manley discloses no potential bias or conflict of interest relating to this article.

\section{REFERENCES}

1. National Kidney Foundation. Kidney Early Evaluation Program. Available at: www.kidney.org/news/keep/KEEPabout.cfm. Accessed August 25, 2007.

2. The United States Renal Data System. The United States Renal Data System Annual Data Report 2006. Available at: www.usrds.org/adr_2006.htm. Accessed August 25, 2007.

3. Bailie GR, Eisele G, Liu L, et al. Patterns of medication use in the RRI-CKD study: focus on medications with cardiovascular effects. Nephrol Dial Transplant. 2005;20:1110-15.

4. Manley HJ, Garvin CG, Drayer DK, et al. Medication prescribing patterns in ambulatory hemodialysis patients: comparisons of USRDS to a large not-for-profit dialysis provider. Nephrol Dial Transplant. 2004;19:1842-48.

5. National Kidney Foundation. KDOQI. Am J Kidney Dis. 2006;47(suppl 3):S1-S145.

6. Go AS, Chertow GM, Fan D, McCulloch CE, Hsu CY. Chronic kidney disease and the risks of death, cardiovascular events, and hospitalization N Engl J Med. 2004;351:1296-305.

7. Sarnak MJ, Levey AS. Epidemiology of cardiac disease in dialysis patients. Semin Dial. 1999;12:69-76.

8. Bakris GL, Williams M, Dworkin L, et al. Preserving renal function in adults with hypertension and diabetes: a consensus approach. National Kidney Foundation Hypertension and Diabetes Executive Committees Working Group. Am J Kidney Dis. 2000;36:646-61.

9. National Heart, Lung, and Blood Institute. The Seventh Report of the Joint National Committee on Prevention, Detection, Evaluation, and Treatment of High Blood Pressure (JNC 7). Available at: www.nhlbi.nih.gov/guidelines/ hypertension/. Accessed September 13, 2007.

10. Lewis EJ, Hunsicker LG, Clarke WR, et al.; Collaborative Study Group. Renoprotective effect of the angiotensin-receptor antagonist irbesartan in patients with nephropathy due to type 2 diabetes. N Engl J Med. 2001;345: 851-60
11. Gaede P, Vedel P, Larsen N, Jensen GV, Parving HH, Pedersen O. Multifactorial intervention and cardiovascular disease in patients with type 2 diabetes. N Engl J Med. 2003;348:383-93.

12. Keane WF, Brenner BM, de Zeeuw D, et al.; RENAAL Study Investigators, The risk of developing end-stage renal disease in patients with type 2 diabetes and nephropathy: the RENAAL study. Kidney Int. 2003;63:1499-507.

13. Erslev AJ. Erythropoietin. N Engl J Med. 1991;324:1339-44.

14. National Kidney Foundation. National Kidney Foundation releases preliminary anemia guideline update. April 12, 2007. Available at: www.kidney. org/news/newsroom/newsitem.cfm?id=380. Accessed November 20, 2007.

15. Kapur A, Malik IS, Bagger JP, et al. The Coronary Artery Revascularisation in Diabetes (CARDia) trial: background, aims, and design. Am Heart J. 2005;149:13-19.

16. Singh AK, Szczech L, Tang KL, et al.; CHOIR Investigators. Correction of anemia with epoetin alfa in chronic kidney disease. N Engl J Med. 2006; 355:2085-98.

17. Drueke TB, Locatelli F, Clyne N, et al.; CREATE Investigators. Normalization of hemoglobin level in patients with chronic kidney disease and anemia. N Engl J Med. 2006;355:2071-84.

18. Besarab A, Bolton WK, Browne JK, et al. The effects of normal as compared with low hematocrit values in patients with cardiac disease who are receiving hemodialysis and epoetin. N Engl J Med. 1998;339:584-90.

19. KDOQI. KDOQI clinical practice guidelines and clinical practice recommendations for anemia in chronic kidney disease: 2007 update of hemoglobin target. Am J Kidney Dis. 2007;50:471-530.

20. Ejerblad E, Fored CM, Lindblad P, et al. Association between smoking and chronic renal failure in a nationwide population-based case-control study. J Am Soc Nephrol. 2004;15:2178-85.

21. Imperatore G, Cadwell BL, Geiss L, et al. Thirty-year trends in cardiovascular risk factor levels among U.S. adults with diabetes: National Health and Nutrition Examination Surveys, 1971-2000. Am J Epidemiol. 2004;160:531-39.

22. Nissenson AR, Collins AJ, Hurley J, Petersen H, Pereira BJ, Steinberg EP. Opportunities for improving the care of patients with chronic renal insufficiency: current practice patterns. J Am Soc Nephrol. 2001;12:1713-20. 


\title{
Chronic Kidney Disease and Medicare
}

\author{
Wendy L. St. Peter, PharmD, FASN, FCCP, BCPS
}

\begin{abstract}
BACKGROUND: Since 1972, Medicare has covered the cost of end-stage renal disease (ESRD). Consequently, Medicare pays a large proportion of ESRD's costs. However, before implementation of Medicare Part D, employer health plans paid most ESRD-associated prescription costs. The ESRD population faces significant hurdles when using the new Part $D$ benefit. To understand those challenges, a basic understanding of Part $D$ is needed.

SUMMARY: Medicare Part D has unique implications for chronic kidney disease (CKD) populations (dialysis, kidney transplant, and CKD patients not on dialysis). Approximately 405,000 ESRD patients were eligible for Part $D$ coverage in 2006. Drug coverage is available for many drugs via Medicare Part B or Part D; however, the Medicare Part B and Part D medication coverage divide is confusing to most clinicians, including pharmacists. Many ESRD patients fall into the dual-eligible category-they are covered by both Medicare and Medicaid. These patients now receive their medications through Part D and must enroll in a prescription drug plan (PDP). However, many PDP plans may not have the drugs that were covered in state-sponsored Medicaid programs. Dialysis-specific issues also abound because of the high-cost, high-use medications needed to treat the numerous comorbid conditions (diabetes, hypertension, anemia, bone and mineral metabolism disorders, and cardiovascular disorders) that flourish in the ESRD population.

CONCLUSION: Managed care demonstration projects are underway to better understand if enrolling these patients into managed care plans with disease management models (i.e., special needs plans) can provide quality care in an effective and efficient manner. Screening patients at high risk for kidney disease, identifying patients with early kidney disease, preventing progression to ESRD, and effectively managing comorbid conditions may reduce long-term medical costs and maintain work productivity. Health care providers need to make an active effort to help CKD patients select kidney-friendly formularies. Medicare requires medication therapy management (MTM) services for certain beneficiaries (called "targeted beneficiaries") enrolled in PDP plans to improve medication optimization. Approximately $80 \%$ of the typical ESRD population has more than 2 targeted comorbidities. Thus, many ESRD patients should be targeted for MTM services, a task that represents an opportunity for pharmacists.
\end{abstract}

J Manag Care Pharm. 2007:13(9):S13-S18

Copyright@ 2007, Academy of Managed Care Pharmacy. All rights reserved.

Author

WENDY L. ST. PETER, PharmD, FASN, FCCP, BCPS, is an associate professor, Department of Pharmaceutical Care and Health Systems, College of Pharmacy at the University of Minnesota, Minneapolis. She is also an investigator with the Chronic Disease Research Group and the United States Renal Data System.

AUTHOR CORRESPONDENCE: Wendy L. St. Peter, PharmD, Associate Professor, College of Pharmacy at the University of Minnesota, 914 S. 8th St., Suite D-206, Minneapolis, MN 55404. Tel.: 612.347.7752; Fax: 612. 347.5878; E-mail: WStPeter@nephrology.org
Oince 1972, Medicare has covered the cost of end-stage renal disease (ESRD). Regardless of age or disability, most $\checkmark$ patients who have ESRD, including dialysis and transplant patients, are eligible for Medicare benefits beginning in the 4th month after diagnosis. The exception is patients who undergo home (peritoneal) dialysis; patients who begin training for peritoneal dialysis can enroll in Medicare in the first month after ESRD diagnosis. Consequently, Medicare pays a large proportion of ESRD's costs. ${ }^{1,2}$

Employer group health plans (EGHPs) are paying an increasing proportion of ESRD costs. In 1997, the 18-month Medicare coordination period for ESRD patients enrolled in EGHPs was extended to 30 months. During the first 3 months (waiting period), the EGHP is typically the primary payer for these ESRD patients. Starting in the 4th month, Medicare becomes the secondary payer. Thus, for 30 months, coverage overlaps and is coordinated. If the patient is still employed, the situation reverses; Medicare becomes the primary payer, and the EGHP becomes the secondary payer. ${ }^{1,2}$

The kidney transplant population (patients who do not receive hemodialysis or peritoneal dialysis as their first option) is addressed differently. In transplant patients, Medicare coverage can begin during the month that the patient's kidney is transplanted. However, Medicare coverage ends 36 months after a successful transplant, and the patient's employer group health insurance resumes if the patient is employed. Medicaid or other medical assistance programs cover patients who are unemployed unless they qualify for Medicare benefits by virtue of age or disability. ${ }^{1,2}$

Medicare Part D has unique implications for chronic kidney disease (CKD) populations (dialysis, kidney transplant, and CKD patients not on dialysis). Beginning January 1, 2006, a plan covering prescription drugs, Medicare Part D, has been available for all beneficiaries who have either Medicare Part A (hospital insurance) or Part B (medical insurance). This prescription drug coverage differs from discounts that were offered by the Medicare-approved drug discount cards in 2004 and 2005. In 2005, approximately 90\% $(\mathrm{N}=306,860)$ of dialysis patients and $69 \%(\mathrm{~N}=98,717)$ of transplant patients were covered by Medicare, either as a primary or secondary insurer. Thus, approximately 405,000 ESRD patients were eligible for Part D coverage in $2006 .^{3}$

\section{Part D's Drug Expenditure Impact}

Before implementation of Medicare Part D, employer health plans paid most ESRD-associated prescription costs. Annually, the Centers for Medicare \& Medicaid Services (CMS) conducts a Medicare Beneficiary Survey, examining about 12,000 Medicare patients; a small segment of those patients have ESRD. Patel and colleagues looked at this data to estimate the impact of the standard Part D benefit on drug expenditures. ${ }^{4}$ They excluded 
adults who were dually enrolled in Medicaid, resulting in 41,617 study subjects, of whom 256 had ESRD. They projected that in 2006, ESRD beneficiaries would have mean annual total and out-of-pocket expenditures approximately twice that of their Medicare peers. Of note, about 28\% of ESRD patients $(\mathrm{n}=134,412)$ in 2005 were dually eligible for both Medicare and Medicaid, and all of these patients should have been enrolled in a Part D plan automatically if they had not chosen a plan. ${ }^{3}$

In terms of Medicare Part D, Medicare has specific rules for ESRD patients. There are 2 types of Medicare Part D plans: a Medicare Advantage Part D plan (called an MAPD) and a standalone prescription drug plan (called a PDP). In most cases, dialysis-dependent patients are allowed to join only a PDP. The only exception is if a Medicare Advantage (MA) plan (also called a Medicare health plan) is called a "special needs plan" and accepts people on dialysis. Patients who are already enrolled in an MAPD when diagnosed with CKD can remain in their plan. Several studies are underway to scrutinize this situation, with an eye toward policy change in the future. New kidney transplant patients can enroll in MA plans as long as they do not need dialysis and they meet Medicare eligibility criteria. ${ }^{1}$

A recent survey conducted by the American Kidney Fund estimates that about 51\% of ESRD patients have enrolled in Part D, and the data suggest that the ESRD population faces significant hurdles when using this benefit. ${ }^{5}$ To appreciate those challenges, a basic understanding of Part D is needed.

Under a standard Part D plan in 2007, patients pay a deductible of about $\$ 265$. Once they have reached the deductible for prescription drugs, they pay as follows:

- Twenty-five percent of yearly costs for covered drugs from $\$ 265$ to $\$ 2,400$. Part D pays $75 \%$.

- One hundred percent of costs for covered drugs from $\$ 2,401$ to $\$ 5,451.25$ (i.e., beneficiaries pay up to $\$ 3,850$ in out-ofpocket costs ["donut hole" or coverage gap]).

- Five percent of costs for covered drugs (or a copayment of $\$ 2$ or $\$ 5$ ), whichever is more, for the remainder of the calendar year (catastrophic coverage).

In the donut hole, patients become responsible for up to $\$ 3,850$ in out-of-pocket expenses. Medicare Part D covers mainly oral prescription drug costs. ${ }^{6}$ CMS has identified 6 categories of special drugs for which PDPs must cover "all or substantially all" drugs (Table 1 ).

Medicare also excludes some drugs for anorexia; weight loss; weight gain; infertility; cosmetic purposes, like hair growth; cold and cough medicines; nonprescription or over-thecounter products; barbiturates; benzodiazepines; and vitamins and minerals (except prenatal vitamins and fluoride preparations). The National Kidney Foundation (NKF) helped successfully lobby CMS to recognize that active vitamin D analogs are essential to treat bone disease in these patients. Active vitamin $\mathrm{D}$ analogs (those that do not rely on activation by the kidney, such as calcitriol, doxercalciferol, and paricalcitol)

\section{TABLE 1 Medicare Part D Covered Drugs}

A PDP must cover "all or substantially all" of the following:
- Cancer medicines
- HIV/AIDS drugs
- Antidepressants
- Antipsychotics
- Anticonvulsants
- Immunosuppressants (unless covered by Part B)
Note: The PDP may not cover every brand name or all doses.
PDP=prescription drug plan.

are now also covered under Part D plans. Kidney-related vitamins (special blends of vitamins that have been formulated specifically for dialysis patients) and oral iron are not covered under Part D. Unfortunately, benzodiazepines are also not covered, although dialysis patients often need benzodiazepines for anxiety or restless leg syndrome, which are pervasive problems. ${ }^{7}$ The so-called "enhanced plans" may cover some excluded drugs, but the premiums are higher for these plans compared with standard plans. It is important to understand that many PDPs do not follow the standard plan template. For instance, many PDP plans waive premiums; others provide generic products during the gap period.

\section{Specific Medication-Related Issues in CKD Patients} Under Part D

\section{Erythropoiesis-Stimulating Agents, Vitamin D, and Iron}

Erythropoiesis-stimulating agents (ESAs) are the most costly drugs paid by Medicare in the ESRD population. Most dialysis patients are covered by Medicare Part A and B and thus are eligible for Medicare Part D. However, Medicare Part D does not cover ESAs for ESRD patients; ESAs are covered by Medicare Part B. This coverage divide is confusing to most clinicians, including pharmacists. Medicare Part B covers separately reimbursable medications given during dialysis, including ESAs, intravenous active vitamin D, or intravenous iron products. Part D also does not cover oral iron products that are used to manage anemia along with ESAs in peritoneal dialysis patients. $^{8}$

In CKD patients who are not yet on dialysis, Part B may pay for ESAs if the CKD patient is Medicare-eligible due to age or disability. Unlike ESRD, CKD alone is not a condition that creates Medicare eligibility. Medicare beneficiaries may have Part B coverage, but the coverage depends on the fiscal intermediary and the criteria it establishes. Many fiscal intermediaries require a diagnosis of anemia or CKD ICD-9-CM (International Classification of Diseases, Ninth Revision, Clinical Modification) codes for patients to be eligible. In addition, they generally will stipulate a certain hemoglobin level. Some also require specific 
serum creatinine or glomerular filtration rate cutoffs for ESA coverage. If Medicare Part B does not cover ESAs, a Part D plan could cover ESAs; in fact, most PDPs include ESAs on their formularies, but they may place them in their formularies' more costly tiers and require prior authorization. ${ }^{8}$

Medications excluded from Part D can be problematic for CKD patients. Although oral active vitamin D products are covered, precursor vitamin D products are not. In CKD patients who have enough kidney function to activate vitamin D, precursor products are appropriate and less costly to treat bone disease. Ergocalciferol, which is recommended by Kidney Disease Outcomes Quality Initiative (KDOQI) practice guidelines, is not covered by Part D. This is also true for oral iron products, such as ferrous sulfate, which are used along with ESA therapy to treat anemia in peritoneal dialysis patients and in CKD patients who are not on dialysis. ${ }^{9}$

\section{Dual-Eligible Issues}

Many ESRD patients fall into the dual-eligible category; that is, they are covered by both Medicare and Medicaid. About 28\% of ESRD patients (transplant and dialysis) were dually enrolled in 2005; the number of dual eligibles has risen substantially from approximately 100,000 patients in 1999 to nearly 135,000 patients in 2005. Before 2006, patients who were dual eligible received their medications through state-funded Medicaid programs. Following Part D implementation, these patients now receive their medications through Part $\mathrm{D}$ and must enroll in a PDP plan. However, many PDP plans may not have the drugs that were covered in patients' state-sponsored Medicaid programs. Dialysis providers need to make an active effort to help patients select kidney-friendly formularies. ${ }^{3}$

\section{Kidney Transplant-Specific Issues}

The majority of kidney transplant patients are Medicare beneficiaries. If the patient has a Medicare-covered transplant, immunosuppressants are covered under Part B for at least 36 months. After 36 months, Part B will continue to pay if the patient has age- or disability-based Medicare coverage. In the circumstance where the patient does not have a Medicarecovered transplant but then becomes eligible for Medicare due to age or disability, immunosuppressants will be covered under Part D, and Part D formularies are required to cover "substantially all" immunosuppressants. ${ }^{2}$

Consider the case example of a transplant patient who resides in Minnesota. He had 2 Medicare-covered transplants in the 1980s. He shifted out of Medicare to employer group health insurance 36 months after his second successful kidney transplant. About 3 years later, he became a Medicare beneficiary again when he became disabled. He recently reached his 65th birthday, and his wife wonders if he should sign up for Medicare Part D. To determine the best course of action, his pharmacist helped his wife enter his medications with com- plete dosing information into Medicare's Compare Medicare Prescription Drug Plans at www.Medicare.gov (also called the Formulary Finder for Prescription Drug Plans, available at http:// formularyfinder.medicare.gov/formularyfinder/selectstate.asp). For immunosuppressants, he was prescribed Cellcept, 500 milligrams, twice a day (which is a proprietary drug) and generic cyclosporine.

The Medicare Prescription Drug Plan Finder identified 51 plans in Minnesota that would match this patient's need. Table 2 compares Option 3, a low-cost plan costing $\$ 4,300$ a year, with 2 other plans that also cover generics in the donut hole period. The monthly costs range from a high of $\$ 110 \mathrm{a}$ month to a low of $\$ 39.50$ a month, and none of the 3 have deductibles.

This patient's medication costs in the initial coverage period before reaching the gap will be considerable, and the Cellcept will account for a large portion of the cost in 2 of the plans. The variability from plan to plan can be significant, and patients must analyze these differences and nuances. Once they enter the gap and become responsible for most of their medication payment, their costs stay about the same in the enhanced plan (which has the highest premium). In the other plans, outof-pocket expense escalates to more than $\$ 430$ per month. Once patients pass through the donut hole, catastrophic coverage begins and all 3 plans have about the same copayment amounts. So although some plans have low copayments initially, in later months costs can be unmanageable for many patients. For transplant patients in particular, many PDPs' elevation of the tier status of immunosuppressants in 2006-2007 to a specialty tier in which a higher cost is borne by the patient seems to have caused a problem. When these patients enter the gap and become responsible for what is to them a staggering cost, they may become nonadherent. They may eliminate doses to try to stretch their prescriptions. Transplant patients who stop taking immunosuppressants or lengthen the dosage interval could experience a rejection. Clinicians' time is frequently wasted dealing with barriers like prior authorization, step-therapy, or quantity limits, especially for higher-tier drugs. There are patient assistance programs but in the gap period, patients who have any income at all rarely qualify for assistance.

Multiple options for immunosuppressants are important for those kidney transplant patients who have their immunosuppressants covered under Part D instead of Part B.

\section{Dialysis}

Dialysis-specific issues also abound because of the high-cost, high-use medications needed to treat the numerous comorbid conditions (diabetes, hypertension, anemia, bone and mineral metabolism disorders, and cardiovascular disorders) that abound in the ESRD population. In fact, the number of medications taken by dialysis patients range from 10 to $12 .{ }^{10}$ Data from 3,768 dialysis patients in the 2003 Medstat MarketScan 


\section{TABLE $2 \longdiv { }$ Medicare Prescription Drug Finder}

\begin{tabular}{|c|c|c|c|}
\hline & $\begin{array}{l}\text { Medicare } \\
\text { BlueRx } \\
\text { Option } 3\end{array}$ & $\begin{array}{l}\text { WellCare } \\
\text { Complete }\end{array}$ & $\begin{array}{c}\text { AARP } \\
\text { MedicareRx } \\
\text { Plan } \\
\text { Enhanced }\end{array}$ \\
\hline Your total annual drug plan cost & $\$ 4,314$ & $\$ 5,161$ & $\$ 4,629$ \\
\hline $\begin{array}{l}\text { Your total drug cost for the rest } \\
\text { of } 2007 \text { ( } 8 \text { months left) }\end{array}$ & $\$ 2,876$ & $\$ 3,095$ & $\$ 3,089$ \\
\hline Prescription premium per month & $\$ 110.30$ & $\$ 39.50$ & $\$ 46.50$ \\
\hline Deductible & $\$ 0$ & $\$ 0$ & $\$ 0$ \\
\hline $\begin{array}{l}\text { Initial coverage limit (amount } \\
\text { you have to spend before your } \\
\text { copay or coinsurance changes) }\end{array}$ & $\$ 0$ & $\$ 2,100$ & $\$ 2,400$ \\
\hline \multicolumn{4}{|c|}{$\begin{array}{l}\text { Your total drug costs after you have met your deductible but before your } \\
\text { total drug costs reach the initial coverage limit. }\end{array}$} \\
\hline allopurinol tablet $300 \mathrm{mg}$ & $\$ 1.74$ & $\$ 0$ & $\$ 5.71$ \\
\hline Cellcept tablet $500 \mathrm{mg}$ & $\$ 104.48$ & $\$ 20.00$ & $\$ 115.01$ \\
\hline Coumadin tablet $7.5 \mathrm{mg}$ & $\$ 10.91$ & $\$ 35.30$ & $\$ 28.00$ \\
\hline cyclosporine capsule $500 \mathrm{mg}$ & $\$ 95.98$ & $\$ 0$ & $\$ 6.00$ \\
\hline lisinopril tablet $5 \mathrm{mg}$ & $\$ 2.24$ & $\$ 0$ & $\$ 6.00$ \\
\hline Mytussin AC $100 \mathrm{mg} / 5 \mathrm{~mL}$ & $\$ 12.58$ & $\$ 12.33$ & $\$ 12.83$ \\
\hline prednisone tablet $5 \mathrm{mg}$ & $\$ 0.80$ & $\$ 0$ & $\$ 2.76$ \\
\hline verapamil capsule $240 \mathrm{mg}$ & $\$ 13.58$ & $\$ 41.72$ & $\$ 6.00$ \\
\hline pravastatin tablet $20 \mathrm{mg}$ & $\$ 7.01$ & $\$ 22.06$ & $\$ 6.00$ \\
\hline Total monthly cost & $\$ 249.22$ & $\$ 131.41$ & $\$ 188.31$ \\
\hline \multicolumn{4}{|c|}{$\begin{array}{l}\text { Your monthly drug costs after your total drug costs reach the initial coverage } \\
\text { limit but before your total out-of-pocket expense equals } \$ 3,850.00 \text {. }\end{array}$} \\
\hline allopurinol tablet $300 \mathrm{mg}$ & $\$ 1.74$ & $\$ 4.20$ & $\$ 5.71$ \\
\hline Cellcept tablet $500 \mathrm{mg}$ & $\$ 104.48$ & $\$ 339.88$ & $\$ 348.73$ \\
\hline Coumadin tablet $7.5 \mathrm{mg}$ & $\$ 10.91$ & $\$ 35.30$ & $\$ 36.61$ \\
\hline cyclosporine capsule $500 \mathrm{mg}$ & $\$ 95.98$ & $\$ 10.00$ & $\$ 6.00$ \\
\hline lisinopril tablet $5 \mathrm{mg}$ & $\$ 2.24$ & $\$ 6.60$ & $\$ 6.00$ \\
\hline Mytussin AC $100 \mathrm{mg} / 5 \mathrm{~mL}$ & $\$ 12.58$ & $\$ 12.33$ & $\$ 12.83$ \\
\hline prednisone tablet $5 \mathrm{mg}$ & $\$ 0.80$ & $\$ 4.90$ & $\$ 2.76$ \\
\hline verapamil capsule $240 \mathrm{mg}$ & $\$ 13.58$ & $\$ 41.72$ & $\$ 6.00$ \\
\hline pravastatin tablet $20 \mathrm{mg}$ & $\$ 7.01$ & $\$ 22.06$ & $\$ 6.00$ \\
\hline Total monthly cost & $\$ 249.22$ & $\$ 476.99$ & $\$ 430.44$ \\
\hline \multicolumn{4}{|c|}{$\begin{array}{l}\text { Your monthly drug costs after your total out-of-pocket expense equals } \\
\$ 3,850.00 \text {. }\end{array}$} \\
\hline allopurinol tablet $300 \mathrm{mg}$ & $\$ 2.15$ & $\$ 2.15$ & $\$ 2.15$ \\
\hline Cellcept tablet $500 \mathrm{mg}$ & $\$ 17.41$ & $\$ 16.99$ & $\$ 17.43$ \\
\hline Coumadin tablet $7.5 \mathrm{mg}$ & $\$ 5.45$ & $\$ 5.45$ & $\$ 5.45$ \\
\hline cyclosporine capsule $500 \mathrm{mg}$ & $\$ 15.98$ & $\$ 15.59$ & $\$ 15.99$ \\
\hline lisinopril tablet $5 \mathrm{mg}$ & $\$ 2.15$ & $\$ 2.15$ & $\$ 2.15$ \\
\hline Mytussin AC $100 \mathrm{mg} / 5 \mathrm{~mL}$ & $\$ 12.58$ & $\$ 12.33$ & $\$ 12.83$ \\
\hline prednisone tablet $5 \mathrm{mg}$ & $\$ 2.15$ & $\$ 2.15$ & $\$ 2.15$ \\
\hline verapamil capsule $240 \mathrm{mg}$ & $\$ 2.26$ & $\$ 41.72$ & $\$ 2.44$ \\
\hline pravastatin tablet $20 \mathrm{mg}$ & $\$ 2.15$ & $\$ 22.06$ & $\$ 2.15$ \\
\hline Total monthly cost & $\$ 62.18$ & $\$ 120.40$ & $\$ 62.24$ \\
\hline \multicolumn{4}{|l|}{ Drug coverage information } \\
\hline allopurinol tablet $300 \mathrm{mg}$ & Generic & Tier 1 & Tier 1 \\
\hline Cellcept tablet $500 \mathrm{mg}$ & Specialty & Tier 2* & $\begin{array}{c}\text { Tier } 4 \\
\text { specialty* }\end{array}$ \\
\hline Coumadin tablet $7.5 \mathrm{mg}$ & Brand & Tier 3 & Tier 2 \\
\hline cyclosporine capsule $500 \mathrm{mg}$ & Generic & Tier $1^{*}$ & Tier $1^{*}$ \\
\hline lisinopril tablet $5 \mathrm{mg}$ & Generic & Tier 1 & Tier 1 \\
\hline Mytussin AC syrup $100 \mathrm{mg} / 5 \mathrm{~mL}$ & $\begin{array}{c}\text { Not } \\
\text { formulary }\end{array}$ & $\begin{array}{c}\text { Not } \\
\text { formulary }\end{array}$ & $\begin{array}{c}\text { Not } \\
\text { formulary }\end{array}$ \\
\hline prednisone tablet $5 \mathrm{mg}$ & Generic & Tier 1 & Tier 1 \\
\hline verapamil capsule $240 \mathrm{mg}$ & Generic & $\begin{array}{c}\text { Not } \\
\text { formulary }\end{array}$ & Tier 1 \\
\hline pravastatin tablet $20 \mathrm{mg}$ & Generic & $\begin{array}{c}\text { Not } \\
\text { formulary }\end{array}$ & Tier 1 \\
\hline
\end{tabular}

* These drugs may be subject to prior authorization, step therapy, or quantity limits.
Commercial Claims and Encounters Database and the Medicare Supplemental and Coordination of Benefits Database (Medstat Group, Inc., Ann Arbor, MI) showed that the average number of Part D medications received by dialysis patients is $8.3+4.4$ (Median 8). This number excluded ESAs as well as intravenous vitamin $\mathrm{D}$, iron, and antibiotics, as these medications are covered by Medicare Part B and include diabetic supplies to administer insulin, which are covered under Part D.

Extrapolation of 4th-quarter data to 12 months revealed that about $33 \%$ of dialysis patients with EGHP insurance spend less than $\$ 2,251$ on Part $\mathrm{D}$ medications per year. These data suggest that about $68 \%$ of dialysis patients will reach the donut hole, where patients are responsible for paying the entire cost of their medications. This is an issue, as some patients may discontinue medications at this point if they cannot afford the full price. Of note, some plans will cover generics during this period. In addition, patients who are dual eligible or who receive extra help will continue to receive medications during this period for lower costs. About 32\% will go past the donut hole and into catastrophic coverage (more than $\$ 5,100$ in covered drug costs, $\$ 3,600$ in out-of-pocket spending). ${ }^{11}$ A limitation of this analysis is that it did not include either cinacalcet or lanthanum carbonate, 2 costly drugs that the U.S. Food and Drug Administration approved after these data were presented. The inclusion of these 2 drugs would be expected to increase the percentage of patients who fell into the donut hole and reached the catastrophic coverage period.

Patel's Medicare Current Beneficiary Survey (which, again, excluded dual-eligible patients) attempted to clarify total annual and out-of-pocket drug spending projected if patients enrolled in a Part D plan. In the population of 256 patients with ESRD and 41,000 patients without ESRD, dialysis patients tended to be much younger, with about half of them being younger than 65 years. Again, dialysis is a covered entity, but patients without ESRD must be at least 65 years old to receive Medicare benefits. ${ }^{4}$ In this analysis, almost $54 \%$ of patients were taking more than 10 medications compared with slightly less than $24 \%$ of patients in the general Medicare population. In terms of drug spending, ESRD medications averaged $\$ 6,488+\$ 765$ annually, compared with $\$ 2,705+\$ 35$ in the population without ESRD. On average, predicted out-of-pocket spending by patients with ESRD under Medicare Part D was $\$ 2,329+\$ 133$ compared with $\$ 1,311+\$ 16$ in patients without ESRD. ${ }^{4}$

Patel also predicted that $70 \%$ of ESRD patients would reach the gap, with June being the month when this would happen most often compared with $43 \%$ of the general Medicare population (the mean month for this group was July). Thirty-nine percent of ESRD patients would qualify for catastrophic coverage (mean month, July), compared with only $14 \%$ of the general population (mean month, September). ${ }^{4}$ These figures are congruent with those produced using Medstat Markets data (above). 
Analyzing further to look at drug cost variability, Patel found the cost variability from month to month was even greater among ESRD patients than non-ESRD patients, suggesting that ESRD patients with moderate to high drug costs will be more vulnerable to cost swings that may increase their risk of reducing or stopping essential chronic medications.

\section{The MTM Requirement}

Medicare requires medication therapy management (MTM) services for certain beneficiaries (called "targeted beneficiaries") enrolled in PDP plans to improve medication optimization. Each PDP defines its own targeted beneficiaries; in general, targeted beneficiaries must have multiple chronic conditions (such as diabetes, asthma, congestive heart failure, dyslipidemia, and hypertension); be taking multiple Part D medications; and have annual Part D medication costs greater than $\$ 4,000$.

Approximately $80 \%$ of the typical ESRD population has more than 2 targeted comorbidities. In terms of costs, almost half spent more than $\$ 4,000$ in $2006 .{ }^{11}$ Thus, many ESRD patients should be targeted for MTM services, and this task represents an opportunity for pharmacists.

Although the data are sparse and not very robust, some indicators support concerns that CKD patients, in general, are experiencing a multitude of problems under Part D. The NKF established the Kidney Medicare Drugs Awareness and Education program to help CKD patients understand Part D. ${ }^{12}$ Subsequently, many CKD patients, their health care providers, and patient caregivers submitted issues regarding Part D to the NKF. Although the NKF did not systematically collect or analyze information, several recurrent themes were expressed, including (1) dual-eligible patients were either automatically or unintentionally enrolled in plans that required premiums (enhanced plans), rather than standard plans that did not have premiums; (2) Part D's copayment amounts exceeded those that the dualeligible patient was accustomed to under Medicaid; (3) a lack of understanding by patients, caregivers, providers, and pharmacists about Medicare Part B versus Part D coverage of immunosuppressant medications, which led to immunosuppressant prescriptions not being filled in a timely manner; and (4) problems paying for medications when the donut hole was reached.

A recent survey of ESRD social workers by the American Kidney Fund supports these findings. Social workers reported that many ESRD patients experienced administrative difficulties both during the enrollment phase and when seeking an appeal; 92\% experienced problems with their plan's formulary. Of those experiencing formulary problems, 32\% reported that their plan did not include some of their medications, 35\% said that they needed to get prior authorization for formulary medications, and $20 \%$ of patients had medications that were excluded by Part D and had difficulties paying their premiums or deductibles. More than $40 \%$ of ESRD patients (excluding non-dual- eligible and low-income subsidy patients) had difficulty paying premiums or deductibles. More than half of dual-eligible or low-income subsidy patients had a "few difficulties" meeting their $\$ 1$ to $\$ 5$ copayment amounts. This survey also pointed out that a good portion of ESRD patients weren't even aware that the Part D program existed. ${ }^{5}$

\section{Conclusion}

Medicare Part D has unique implications for the CKD populations. Drug coverage is available for many drugs via Medicare Part B or Part D; the Medicare Part B and Part D medication coverage divide is confusing to most clinicians, pharmacists, and patients. Many ESRD patients fall into the dual-eligible categorythey are covered by both Medicare and Medicaid.

ESRD is a costly condition. From the diagnosis of CKD to the time ESRD develops, the costs grow and patients' energy and productivity decline. EGHPs are paying an increasing proportion of costs for ESRD patients. Managed care demonstration projects are underway to better understand if enrolling these patients into managed care plans with disease management models (i.e., special needs plans) can provide quality care in an effective and efficient manner. Screening patients at high risk for kidney disease, identifying patients with early kidney disease, preventing progression to ESRD, and effectively managing comorbid conditions may reduce long-term medical costs and maintain work productivity. Available data suggest that CKD patients are experiencing a variety of problems under Medicare Part D. Adequate access to essential chronic medications under Medicare Part D or within managed health plans is critical to prevent progression of kidney disease, prevent rejection of kidney transplants, and maintain health in dialysis patients.

\section{DISCLOSURES}

Author Wendy L. St. Peter discloses that she receives grant/research support from Amgen, Inc. and GenZyme Corporation.

\section{REFERENCES}

1. Centers for Medicare \& Medicaid Services. ESRD Medicare guidelines. Available at: www.kidney.org/professionals/cnsw/pdf/ESRD_medicare_ guidelines.pdf. Accessed November 29, 2007.

2. Centers for Medicare \& Medicaid Services. Medicare coverage of kidney dialysis and kidney transplant services. Available at: www.medicare.gov/ Publications/Pubs/pdf/10128.pdf. Accessed October 3, 2007.

3. The United States Renal Data System. The United States Renal Data System Annual Data Report 2007. Available at: www.usrds.org/adr.htm. Accessed September 25, 2007

4. Patel UD, Davis MM. Falling into the doughnut hole: drug spending among beneficiaries with end-stage renal disease under Medicare Part D plans. J Am Soc Nephrol. 2006;17:2546-53

5. Avelere Health, LLC, National Kidney Foundation. ESRD patients' experience with Medicare Part D. Available at: www.kidneyfund.org/PDF/ AKF_Part_D_Study.pdf. Accessed October 3, 2007. 
6. The Kaiser Family Foundation. Data spotlight: standard Medicare prescription drug benefit, 2007. Available at: www.kff.org/charts/111306.htm. Accessed October 3, 2007

7. Murtagh FE, Addington-Hall J, Higginson IJ. The prevalence of symptoms in end-stage renal disease: a systematic review. Adv Chronic Kidney Dis. 2007; 14: 82-99

8. Centers for Medicare \& Medicaid Services. Medicare Part B versus Part D coverage issues. Available at: www.cms.hhs.gov/PrescriptionDrugCovGenIn/ Downloads/PartBandPartDdoc_07.27.05.pdf. Accessed October 3, 2007.

9. National Kidney Foundation. K/DOQI clinical practice guidelines for bone metabolism and disease in chronic kidney disease. Available at: www.kidney. org/professionals/KDOQI/guidelines_bone/index.htm. Accessed October 3, 2007.
10. Grabe DW, Low CL, Bailie GR, Eisele G. Evaluation of drug-related problems in an outpatient hemodialysis unit and the impact of a clinical pharmacist. Clin Nephrol. 1997;47:117-21.

11. St. Peter WL, Wang C, Daniels F, Li Q. Data presented at the 2005 American Society of Nephrology meeting. Available at: www.usrds.org/2005/pres/USRDS_ talk_ASN_11_10_05_files/frame.htm. Accessed September 27, 2007.

12. The Kidney Medicare Drugs Awareness and Education Initiative. Kidney drug coverage. Available at: www.kidneydrugcoverage.org/. Accessed October 3, 2007. 


\title{
Employer Challenges With the Chronic Kidney Disease Population
}

\author{
Sean Sullivan, JD
}

\begin{abstract}
BACKGROUND: Employers have not yet begun to focus on chronic kidney disease (CKD) as a major health issue in the workplace. CKD is part of the metabolic and cardiovascular health burden, which is a major threat to the future survivability of the employer-based health financing system. It represents one opportunity for employers to intervene now to save health care costs later.
\end{abstract}

OBJECTIVE: To describe the impact of CKD in non-Medicare payer populations (i.e., employer group health plans) and the importance of early screening and detection of the disorder to improve patient quality of life and reduce the future cost burden of this disease.

SUMMARY: Twenty million Americans suffer from CKD, and 20 million more are at elevated risk; soon, 1 in 9 Americans will have CKD. Control of comorbidities may slow its progression, and 2 are critical-type 2 diabetes and hypertension. Health care costs are made up of 2 categories and 5 subcategories: direct costs, which are (1) inpatient, (2) outpatient, and (3) drug costs-roughly three quarters of the total costs associated with patients who have nondialysis renal insufficiency —and indirect costs, which are lost productivity due to (4) disability and (5) absenteeism.

CONCLUSION: CKD should be considered part of a larger picture of metabolic health. As CKD is related to cardiometabolic health, it is beginning to capture payers' and purchasers' interest. Investing health care dollars today to identify the disease and slow its progression should improve patient quality of life and reduce the future cost burden of this disease and its associated conditions.

J Manag Care Pharm. 2007:13(9):S19-S21

Copyright $\odot$ 2007, Academy of Managed Care Pharmacy. All rights reserved.

\section{Author}

SEAN SULLIVAN, JD, is cofounder, president, and chief executive officer, Institute for Health and Productivity Management, and chief executive officer, Initiative for Value-Based Health Benefits. He is also editor-in-chief of the quarterly magazine Health \& Productivity Management.

AUTHOR CORRESPONDENCE: Sean Sullivan, JD, President \& CEO, Institute for Health and Productivity Management, Gainey Ranch Center, 7702 E. Doubletree Ranch Rd., Suite 300, Scottsdale, AZ 85258. Tel.: 480.607.2660.E-mail: sean@ihpm.org
E mployers have historically focused on health care issues with immediate cost implications, such as mental health or diabetes. However, for close to a decade, the Institute for Health and Productivity Management (IHPM) has been working with employers to improve their employees' health and to maximize the employers' return on their investment in workers health. Increasingly, this evidence-based work is attracting attention. Good, solid information on total costs, including lost productivity, supports a change in how employers will view and pay for health care—as a targeted "investment" in better health and as a business asset, rather than just a "cost" of doing business.

\section{The Long-Term Perspective: CKD}

Chronic kidney disease (CKD) is an important and expensive workplace issue that has typically been overlooked by employers in favor of issues that affect a greater proportion of the population, such as metabolic health and mental health. IHPM held a series of employer advisory boards on CKD last year, structured to help employer medical directors consider how CKD fits into a larger picture of metabolic disease and cardiovascular health. IHPM research and study results demonstrate that metabolic and cardiovascular risk factors and conditions create a significant cost burden for employers and a potential threat to the future of employer-based health financing. CKD is part of the overall health care cost burden, and represents one opportunity for employer investment and intervention with the goal of reducing future health care costs. Both productivity and medical costs contribute to the staggering implications of inaction. Four facts highlight the need for employer-based health care plans to begin addressing CKD more aggressively:

1 Twenty million Americans suffer from CKD, while 20 million more are at elevated risk. ${ }^{1}$

2. Nearly half of patients with CKD are unaware they have it. ${ }^{1}$ Without aggressive management, kidney dysfunction progresses to end-stage renal disease (ESRD), with subsequent dialysis or transplant needs. ${ }^{1}$

3. Control of CKD comorbidities may slow CKD's progression. Control of type 2 diabetes and hypertension is known to slow CKD progression, while efforts to address other areas of cardiometabolic health are also considered critical. ${ }^{2}$

4. Anemia treatment in CKD is associated with improved outcomes and decreased health care costs. ${ }^{3}$

CKD is a costly disease for every payer type. Treatment costs roughly double as CKD progresses from one stage to the next. Data from the IHPM database (2001) indicate that insurance claims range from $\$ 5,000$ to $\$ 12,000$ per patient per year as a patient proceeds from stage 1 to stage 2 . At stages 3 and 4 , claims increase to $\$ 15,000$ to $\$ 28,000$ per year, partly due to serious associated comorbidities such as heart failure and atherosclerosis. At stage 5, ESRD, costs can exceed $\$ 70,000$ per patient per year. ${ }^{3,4}$ It is reasonable to assume these costs will 
increase if nothing is done to halt the progression of CKD, making it a financially important issue for employers.

\section{CKD's Workplace Costs}

Health care costs can be sorted into 2 main categories and 5 subcategories. The first main category is direct costs, which are (1) inpatient, (2) outpatient, and (3) drug costs—roughly three quarters of the total costs associated with patients who have nondialysis renal insufficiency. The second main category is indirect costs, which are lost productivity due to (4) disability and (5) absenteeism. CKD has direct and indirect costs that ripple into the workplace. Employees with CKD may be eligible for disability, while others may frequently be absent due to illness or medical appointments. Generally, disability and absenteeism account for about $25 \%$ of the total health-related costs of CKD. ${ }^{4}$ As many employers no longer divide workplace leave into sick days and other types of leave, this estimate may be low.

A 6th type of cost is worthy of discussion. "Presenteeism" is the performance lost daily in the workplace when employees come to work in spite of illness, which has negative repercussions on business performance. Researchers have established presenteeism measurement databases for conditions including depression, seasonal allergies, and migraine. Although presenteeism has not yet been measured for CKD, researchers have been able to measure presenteeism in kidney disease. ${ }^{3}$

\section{Collaborating to Fully Understand the Economic Impact of Anemia}

Anemia is a serious concern and of considerable cost in CKD. Although much work has been done concerning anemia resulting from chemotherapy treatment of cancer patients, little work has looked at the economic impact of untreated anemia in nondialysis CKD patients. A Nephrology Outcomes/Collaborative Research study examined the health and disability claims of 600,000 people over 3.5 years (January 1998 to June 2001) (Table). Seven Fortune 500 companies provided information for the combined database. The researchers determined that of 992 CKD patients who were not receiving anemia therapy, 176 had an ICD-9-CM (International Classification of Diseases, Ninth Revision, Clinical Modification) coded diagnosis of anemia. Using a multivariate regression analysis, they analyzed the costs specific to anemia for cardiovascular disease, diabetes, liver cirrhosis, transplantation, hypertension, chemotherapy, and Charles Comorbidity Index, as well as age, sex, and health plan region. They further examined the anemia data using univariate and multivariate analyses on the untreated anemia population to look at the associated direct and indirect costs. ${ }^{5}$

The statistically significant findings from the univariate model in monthly cost differences indicate that the $176 \mathrm{CKD}$ patients who were not treated for anemia incurred 2.5 more direct costs and 1.4 more indirect costs than did the CKD patients who did not have an ICD-9-CM code for anemia. ${ }^{5}$ The

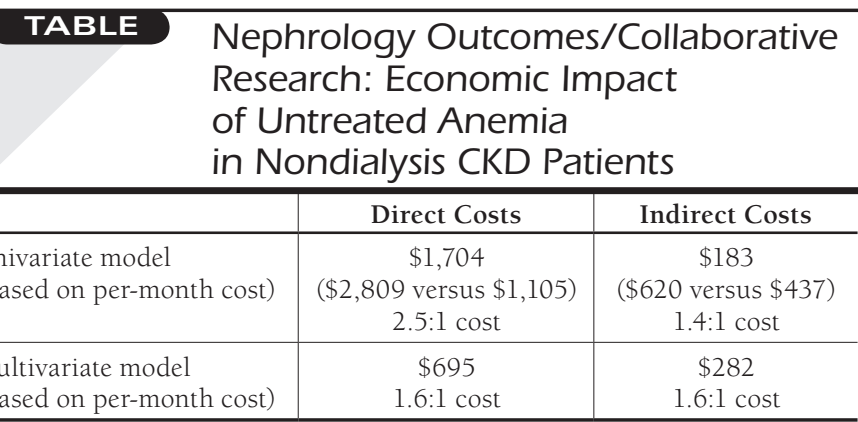

Adapted from Mody SH (2004). ${ }^{6}$

$C K D=$ chronic kidney disease

multivariate model, which takes into account comorbidities and other factors, indicates that for nondialysis CKD patients, the indirect cost ratio was approximately 1.6:1. The direct cost difference was also 1.6:1.

Recognizing that predicted increases in ESRD incidence, prevalence, and cost between now and 2010 will be significant and that slowing ESRD's progression could reduce costs, Trivedi et al. developed a mathematical model to assess the economic impact of decreasing chronic renal failure (CRF) progression by $10 \%, 20 \%$, and $30 \%{ }^{7}$ The model indicates that without intervention, the average decline in glomerular filtration rate (GFR) in subjects with CRF is approximately $7.56 \mathrm{~mL}$ per minute per year. The model calculates the time gained before onset of ESRD for different degrees of reduction in the progression of CRF. Slowing GFR decline by $10 \%, 20 \%$, or $30 \%$ over 10 years in patients with GFRs of $60 \mathrm{~mL}$ per minute or less was calculated to result in reduced medical care spending of $\$ 18.5$ billion, $\$ 39$ billion, and $\$ 60$ billion, respectively. In patients with GFRs of $30 \mathrm{~mL}$ per minute or less, a 10\%, 20\%, and 30\% decrease in the rate of decline would result in estimated cumulative savings over 10 years equal to $\$ 9.06, \$ 19.98$, and $\$ 33.37$ billion, respectively. Of interest were the patientperspective findings. Approximately four fifths of subjects with CRF $(n=113)$ considered a few weeks of being dialysis free to be of great value $(P \leq 0.001)$, which could be achieved with a $10 \%$ reduction in the rate of decline in GFR. ${ }^{7}$ In addition, as determined by a written questionnaire, patients expressed a willingness to follow a restricted diet, take 6 extra medications per day, and make 6 extra office visits per year to slow the progression of renal failure. This mathematical model suggests that intensive renal-protective efforts beginning before or at stage 3 CKD could potentially result in a large cost savings. ${ }^{8}$

Most government costs will be accrued in the population of CKD patients who are no longer working, as many of these patients will qualify for Medicare services. Because employers pay a large share of the cost of Medicare through taxes, the relevance of CKD costs to employer health plans is partly 
unaccounted for. The costlier the Medicare population becomes, the more employers may have to contribute through employer Social Security taxes to fund Medicare. Employers' contribution to Medicare generally is not calculated as part of their total health care costs, but an economist's definition of total costs certainly would include it.

The president's budget for this year proposes shifting some of Medicare's future CKD-associated costs to private payers and specifically to employers by extending the time before patients would be Medicare eligible. ${ }^{8}$ The proposal would increase the time from 30 to 60 months before Medicare becomes the secondary payer for employers who cover retiree health costs for ESRD patients. In 2007 alone, projected savings for the government are $\$ 50$ million. Between 2007 and 2011, the projected savings increase to $\$ 470$ million. Shifting costs of this magnitude to employers who provide coverage for these employees and for retirees should heighten their awareness of failing to acknowledge this problem and intervene more aggressively.

\section{The CKD-Cardiometabolic Link}

CKD is frequently related to overall cardiometabolic health, which is beginning to capture payers' and purchasers' interest. Although the term "metabolic syndrome" is being debated and refined, most stakeholders agree that a related set of risk factors-cardiovascular and metabolic (mostly related to diabetes), with obesity a key component—collectively determine cardiometabolic health. Three quarters of diabetics die from heart disease or stroke, and the key factor may be atherosclerosis.

Many employer health plans and their medical leaders have little awareness of CKD's prevalence and total cost impact in the workplace. As a result of IHPM's experience with plans and employers, IHPM recommends that plans and employers consider CKD as an endpoint of diabetes and hypertension and integrate various cardiometabolic health/disease management efforts. Focusing attention on optimizing drug therapies that treat CKD comorbidities and slow its progression should prove to be one avenue of improving overall care of employees with CKD.

\section{Conclusion}

Globally, health care policy makers and researchers are beginning to place CKD in the larger framework of cardiovascular and metabolic health. Health care costs are a business issue and not just a medical issue. As shown in the Trivedi et al. ${ }^{7}$ model assessing the economic impact of decreasing CRF progression, slowing the progression of CKD will result in estimated cumulative savings over 10 years of $\$ 9.06$ to $\$ 33.37$ billion. Ultimately, slowing disease progression should lead to improved patient quality of life while reducing the cost burden of this disease and its associated conditions.

\section{DISCLOSURES}

Author Sean Sullivan discloses no potential bias or conflict of interest relating to this article.

\section{REFERENCES}

1. National Kidney Foundation. K/DOQI clinical practice guidelines for chronic kidney disease: evaluation, classification, and stratification. Am J Kidney Dis. 2002;39(2 suppl 1):S50

2. Kausz AT, Khan SS, Abichandani R, et al. Management of patients with chronic renal insufficiency in the Northeastern United States. J Am Soc Nephrol. 2001;12:1501-07.

3. McClellan W, Aronoff SL, Bolton WK, et al. The prevalence of anemia in patients with chronic kidney disease. Curr Med Res Opin. 2004;20:1501-10.

4. Boyce SP, Buteau S, Cremieux PY, Mody SH, Piech CT. Value in Health. 2003; 6(3):286 (Abstract PRK4)

5. Mody SH. Reducing the economic and clinical burden of CKD in the managed care setting. Biotech Healthcare. 2004;56-61.

6. Mody SH. Economic impact of untreated anemia in nondialysis chronic kidney disease patients: an employer's perspective. J Am Soc Nephrol. 2003;14:457A. (Abstract SA-PO727).

7.Trivedi HS, Pang MM, Campbell A, Saab P. Slowing the progression of chronic renal failure: economic benefits and patients' perspectives. Am J Kidney Dis. 2002;39:721-29.

8. Geisel J. Budget shifts more costs of renal disease to employers. Business Insurance. 2006;36: February 13. Available at: http://findarticles.com/p/articles/ mi_hb5252/is_200602. 


\section{Managed Care to Medicare: Sharing the Burden of Chronic Kidney Disease}

This activity has been planned and implemented in accordance with the Essential Areas and Policies of the Accreditation Council for Continuing Medical Education (ACCME) through the joint sponsorship of Creative Educational Concepts, Inc. (CEC) and AMCP Horizons, LLC. CEC is accredited by ACCME to provide continuing medical education for physicians. CEC designates this educational activity for a maximum of 1.5 AMA PRA Category 1 Credits. Physicians should only claim credit commensurate with the extent of their participation in the activity.

AE.

Creative Educational Concepts, Inc. is accredited by the Accreditation Council for Pharmacy Education as a provider of continuing pharmacy education. This program has been assigned ACPE Universal Program No. 245-999-07-109-H04-P and will award 1.5 contact hours (0.15 CEUs) of continuing pharmacy education credit. CEC complies with the Criteria for Quality for continuing education programming. Statements of credit will be issued automatically online. (Release date: December 3, 2007; Expiration date: December 2, 2008)

Continuing Education for this activity is processed solely through the AMCP.org Online Learning Center site at www.amcp.org (Learning Center/Online CE). No mailed forms will be accepted.

The posttest worksheet (below) is provided to assist you in marking your answers prior to entering the online CE center for submission; these pages cannot be submitted for CE credits.

In order to receive $\mathrm{CE}$ credit for this activity, you must complete the following forms online:

1. "Managed Care to Medicare: Sharing the Burden of Chronic Kidney Disease" on the AMCP.org Online Learning Center site. To receive CE credit, you must receive a score of at least $70 \%$. You will have 2 opportunities to pass the posttest.

2. Program Evaluation form

Upon successful completion of this program, you will automatically receive your CE statement. Your CE credits will be automatically archived and tracked for you on the AMCP.org Online Learning Center site. All information is kept confidential.

Note: There is a $\$ 10$ processing fee for nonmembers. (See payment instructions on site.)

\section{Posttest Worksheet: Managed Care to Medicare: Sharing the Burden of Chronic Kidney Disease}

1. How many people in the United States have chronic kidney disease (CKD)?
a. 1 in 5
b. 1 in 9
c. 1 in 16
d. 1 in 25

2. Which conditions put people at risk for CKD?
a. Diabetes
b. Hypertension
c. Kidney stones
d. A and B
e. All of the above

3. Why are black Americans and ethnic groups at increased risk for kidney disease?

a. Diabetes is more common.

b. Hypertension is more common.

c. Diabetes and high blood pressure tend to run in families.

d. All of the above. 
4. The current health care system in the United States results in delayed detection of CKD, because of

a. overuse of different management principles and protocols.

b. lack of guidelines to deal with disease progression.

c. patients and their caregivers not being involved in their care.

d. lost time concentrating on underlying comorbidities.

5. The definition of CKD is

a. kidney damage - structural or functional abnormalities-for $\geq 3$ months.

b. increased glomerular filtration rate (GFR).

c. pathological normalities of the blood or urine.

d. GFR $>60 \mathrm{~mL}$ per minute per $1.73 \mathrm{~m}^{2}$ for $\geq 3$ months, with or without kidney damage.

6. Staging the progress of CKD as stages 1 through 5 has been occurring for a number of years. Which stage of CKD is most commonly identified?
a. Stage 2
b. Stage 3
c. Stage 4
d. Stage 5

7. Of the 55,000 patients who have been screened via the KEEP process, approximately 13,000 patients with CKD have been identified. Twenty-nine percent of the patients, nearly 1 out of 3 patients, had these high risk factors:
a. Diabetes
b. Hypertension
c. Sibling or a parent with CKD
d. All of the above

8. Delaying progression of CKD may be accomplished by
a. reduction of hemoglobin to $<12$ g per $\mathrm{dL}$.
b. antidepressant therapy.
c. glucose and blood pressure control.
d. induction of anemia.
e. avoidance of lipid-lowering medications.

9. Cardiovascular disease mortality rates are 15 times higher in end-stage renal disease (ESRD) patients compared with people who do not have ESRD.
a. True
b. False

10. Compared with a blood pressure of $140 / 90 \mathrm{~mm} \mathrm{Hg}$, how much does a blood pressure of 130/80 $\mathrm{mm} \mathrm{Hg}$ slow progressive renal disease?
a. $25 \%$
b. $40 \%$
c. $50 \%$
d. $65 \%$

11. A 35-year-old female has CKD and a serum creatinine of $1.5 \mathrm{mg}$ per $\mathrm{dL}$ (creatinine clearance $=60 \mathrm{~mL}$ per minute). Approximately when will she require dialysis?

a. In 5 years

b. In 8 to 9 years

c. In 25 years

d. It depends on how well her blood pressure is controlled.

12. One of the consequences of anemia in CKD is
a. right ventricular hypertrophy.
b. precipitation of congestive heart failure (CHF).
c. eradication of angina.
d. reductions in Alc.

13. The CHOIR study was designed to investigate the optimal level of hemoglobin correction in patients with CKD. Patients were treated with epoetin alfa to a target hemoglobin of either $11.3 \mathrm{~g}$ per dL (low-hemoglobin group) or $13.5 \mathrm{~g}$ per $\mathrm{dL}$ (high-hemoglobin group). Study results showed that patients in the low- hemoglobin group had a. a significantly increased risk of heart failure.

b. a decreased need for kidney transplant.

c. an increased risk of any serious adverse event.

d. a lower risk of death, myocardial infarction, or stroke.

14. Clinicians are cautioned to use the lowest dose of erythropoiesis-stimulating agents (ESAs) that will gradually increase the hemoglobin concentration to the lowest level sufficient to avoid the need for red blood cell transfusion. The reason is that

a. ESAs increase the risk for death and for serious cardiovascular events when administered to target a hemoglobin $>12$ g per dL.

b. ESAs increase the risk for death and for serious cardiovascular events when administered to target a hemoglobin $<12$ g per dL.

c. ESAs decrease the risk for death and for serious cardiovascular events when administered to target a hemoglobin $>12$ g per dL.

d. more than one of the above apply.

15. Angiotensin-converting enzyme inhibitors and angiotensin II receptor blockers are effective in slowing the progression of kidney disease characterized by microalbuminuria in hypertensive patients with diabetes.
a. True
b. False 
16. Medicare pays for treatment of ESRD, and most patients who develop ESRD are eligible for Medicare benefits (e.g., dialysis, kidney transplantation). Which of the following statements is false?

a. Medicare coverage generally starts 30 days after ESRD is determined.

b. Patients who receive training for home dialysis are eligible for Medicare benefits at the start of ESRD.

c. Patients covered by an employer group health plan (EGHP) will be covered by the health plan for 33 months from the start of ESRD.

d. For patients covered by an EGHP, Medicare coverage will start in the 4th month as the secondary payer.

17. Medicare coverage can start the month the patient is admitted to a Medicare-approved hospital for a kidney transplant. Medicare coverage lasts for 36 months after a successful transplant, but after 36 months,

a. an EGHP, other health plans, Medicaid, or other assistance programs do not need to cover the patient's costs.

b. the patient is no longer eligible for Medicare benefits.

c. the patient will go back to his/her EGHP.

d. if the patient is not employed, Medicare will cover the patient after 30 days.

e. patients with Medicare benefits because of age or disability will be covered under Part B.

18. What was the entity that paid the largest proportion of prescription drug coverage for ESRD patients before the inception of Medicare Part D?
a. Medicaid
b. Employer plan
c. Patient
d. Other

19. Most ESRD dialysis patients
a. can sign up with a Medicare Advantage Part D plan (MAPD) or a stand-alone prescription drug plan (PDP).
b. if they are "successful" kidney transplant patients, cannot join an MAPD, but they can join a stand-alone PDP.
c. cannot sign up with an MAPD, only a stand-alone PDP.
d. can sign up for Medicaid.

20. Assuming a dialysis patient is covered by Medicare Part A or $\mathrm{B}$, the Part D plan is responsible for ESAs.
a. True
b. False

21. Part B covers separately reimbursable medications given during or at a dialysis session. Examples of Part B covered drugs include
a. ESAs if Part D does not cover.
b. IV precursor vitamin $\mathrm{D}$ agents.
c. over-the-counter iron products.
d. oral antibiotics.

22. Part D will cover most oral medications. Examples of covered drugs include
a. precursor Vitamin D products (ergocalciferol or cholecalciferol).
b. benzodiazepines.
c. ESAs if Part B does not cover.
d. oral iron.

23. Fifty-three percent to 54\% of CKD patients will be on 10 to 12 medications
a. by stage 3 .
b. by stage 4 .
c. by stage 5 (ESRD).
d. after a kidney transplant.

24. Of ESRD patients, $70 \%$ reach the gap and 39\% go into catastrophic coverage. What happens to the other $31 \%$ of ESRD patients?
a. They can sign up with a PDP.
b. They are assigned to an MAPD.
c. They will remain in the "donut hole."
d. More than one of the above. 



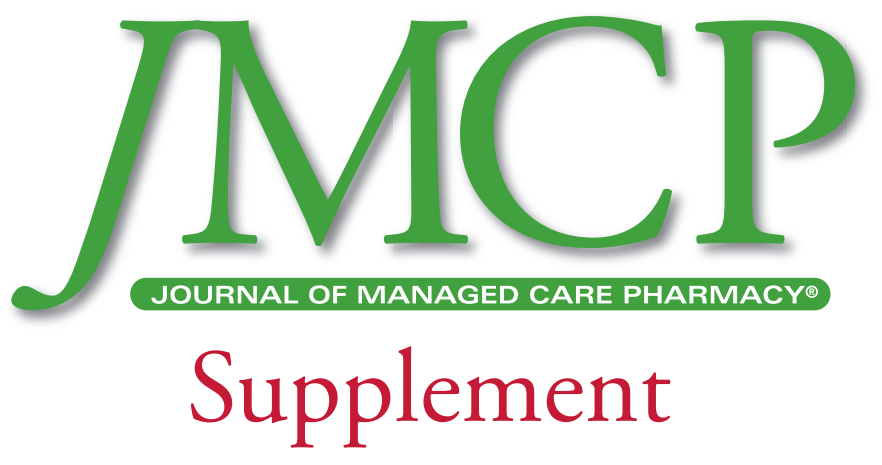

